\title{
O DIREITO DE AUTOR COMO UM DIREITO AO ACESSO GARANTINDO A PARTICIPAÇÃO CULTURAL POR MEIO DA PROTEÇÃO DOS INTERESSES DOS CRIADORES ${ }^{*}$
}

COPYRIGHT COMME UN DROIT A GARANTIR L'ACCES A LA PARTICIPATION CULTURELLE PAR LA PROTECTION DES INTERETS DES CREATEURS

CHRISTOPHE GEIGER*

O Direito de autor, originalmente concebido como um direito para proteger o autor e prover incentivos para o benefício da sociedade, hoje em dia é percebido cada vez mais como um mecanismo em benefício de "grande corporações, impessoais e mal-amadas". A dimensão social do direito de autor vem sendo progressivamente desconsiderada por políticos para o benefício de concepções estritas, individualistas e mesmo egoístas. No discurso recente de fortalecimento dos meios de proteção, o direito de autor é freqüentemente apresentado mais como um mecanismo de proteção do investimento do que um veículo de progresso cultural $e$ social. Nesse contexto, o enriquecimento e o futuro da sociedade são representados na retórica dos grandes players econômicos como "um subproduto afortunado da intitulação privada".

\footnotetext{
*Tradução de Leonardo Machado Pontes, doutorando pelo CEIPI (2015). Revisão do Professor Dr. Denis Barbosa.

*Professor Associado, Diretor Geral e Diretor do Departamento de Pesquisa do Centro para Estudos Internacionais da Propriedade Intelectual (CEIPI), Universidade de Estrasburgo, França. Pesquisador sênior afiliado ao Instituto Max Planck para Inovação e Competição, Munique. Esse artigo se baseia em pesquisas prévias publicadas pelo autor, considerando a função social da propriedade intelectual e, em particular, a relação entre os direitos fundamentais e o direito de autor: "The Social Function of Intellectual Property Rights, Or how Ethics can Influence the Shape and Use of IP law", in: G.B. Dinwoodie (ed.), Intellectual Property Law: Methods and Perspectives (Cheltenham, UK/Northampton, MA, Edward Elgar, 2014), p. 153; ““Constitutionalising' Intellectual Property Law?, The Influence of Fundamental Rights on Intellectual Property in Europe”, 37(4) IIC 371 (2006); "Flexibilising Copyright Remedies to the Privatisation of Information by Copyright Law", 39(2) IIC 178 (2008); "Implementing Intellectual Property Provisions in Human Rights Instruments: Towards a New Social Contract for the Protection of Intangibles", Max Planck Institute for Innovation and Competition Research Paper No. 1410, breve em: C. Geiger (ed.), Research Handbook on Human Rights and Intellectual Property (Cheltenham, UK/ Northampton, MA, Edward Elgar, 2015). O autor é grato a Elena Izyumenko, doutoranda pelo CEIPI, por sua ótima assistência na pesquisa e suporte editorial.
} 
Isso vem provocando importantes contra-reações: o direito de autor vem sendo percebido principalmente como um direito de proibir, de sancionar e punir; a infração ao direito de autor nas gerações mais novas evoluindo em atos de protesto, levando a uma séria crise de legitimidade. Mesmo em relação aos autores, o direito de autor é cada vez mais percebido como um impedimento ao processo criativo, como o sucesso dos chamados modelos de “conteúdo aberto” claramente demonstram.

Esses desenvolvimentos atestam urgentemente a necessidade de repensar o direito de autor para adaptar suas regras a sua característica inicial dual: 1) um direito para assegurar e organizar participações culturais e o acesso aos trabalhos criativos (aspecto do acesso); e 2) a garantia de que os criadores participem justamente dos frutos da exploração econômica de seus trabalhos (aspecto da proteção). Evitar a privatização da informação pelo direito de autor e assegurar que os bens culturais ainda estejam disponíveis para futuras inovações pode significar a necessidade de (re)conceber o direito de autor como um direito ao acesso e não como um direito de proibir, desse modo enfatizando a natureza inclusiva e não exclusiva da proteção do direito de autor.

Introdução

"It is never too late to give up our prejudices. No way of thinking or doing, however ancient, can be trusted without proof. What everybody echoes or in silence passes by as true today may turn out to be falsehood tomorrow, mere smoke of opinion, which some had trusted for a cloud that would sprinkle fertilizing rain on their fields. What old people say you cannot do, you try and find that you can. Old deeds for old people, and new deeds for new".

(Henry David Thoreau, Walden; or, Life in the Woods, Boston, Ticknor and Fields, 1854, p. 11.)

O Direito de autor, originalmente concebido como um direito para proteger o autor e prover incentivos para o benefício da sociedade, hoje em dia é percebido cada vez mais como um mecanismo em benefício de "grandes corporações, impessoais e mal-amadas". ${ }^{1}$ Como demonstram os resultados de um grande estudo sobre a percepção dos europeus sobre a Propriedade Intelectual (PI), mais de $40 \%$ dos cidadãos da EU, quando questionados a respeito

\footnotetext{
${ }^{1}$ J.C. Ginsburg, "How Copyright Got a Bad Name for Itself”, 26(1) Columbia Journal of Law \& the Arts 61 (2002), at 61.
} 
de quem mais se beneficiaria do sistema, responderam: asgrandes corporações e artistas famosos, ${ }^{2}$ mas não os criadores e a sociedade de uma maneira geral.

Assim, a dimensão social,inerente do direito de autor, vem sendo progressivamente desconsiderada por políticos para o benefício de concepções estritas, individualistas e mesmo egoístas. No discurso recente de fortalecimento dos meios de proteção, o direito de autor é frequentemente apresentado mais como um mecanismo de proteção ao investimento ${ }^{3}$ do que um veículo de progresso cultural e social. Nesse contexto, o enriquecimento e o futuro da sociedade são representados na retórica dos grandes players econômicos como "um subproduto afortunado da intitulação privada”. ${ }^{4} U m$ bom exemplo desse discurso pode ser ilustrado nas publicidades de campanhas que foram lançadas alguns anos atrás pela indústria musical, mostrando jovens usuários da internet presos atrás das grades por terem compartilhado arquivos de música, utilizando a clássica analogia do "furto” de bens tangíveis, em que o download ilegal seria o mesmo que entrar em um shopping e furtar. ${ }^{5}$ Isso vem provocando importantes contra-reações: o direito de autor vem sendo percebido principalmente como um direito de proibir, de sancionar e punir; a infração ao direito de autor, predominantemente nas gerações mais novas, vem evoluindo em atos de protesto $^{6}$ e levando a uma séria crise de legitimidade. ${ }^{7}$ Mesmo em relação

\footnotetext{
${ }^{2}$ OHIM Report, European Citizens and Intellectual Property: Perception, Awareness and Behaviour, novembro de 2013, p. 66

${ }^{3}$ Ver, e.g, M. Vivant, "Propriété intellectuelle et nouvelles technologies, À la recherche d'un nouveau paradigm”, in: Université de tous les savoirs, vol. 5: Qu'est ce que les technologies? (Paris: Odile Jacob, 2001), 201 et seq. Essa conclusão pode ser igualmente atingida no direito de patentes, onde a proteção da criatividade e inovação parece ter se tornado subordinada à proteção do investimento. Como B. Remiche, “Marchandisation et brevet”, in: M. Vivant (ed.), Propriété intellectuelle et mondialisation (Paris: Dalloz, 2004), 127 corretamente enfatiza, nós temos testemunhando nesses vários anos uma mudança no centro de interesses do direito, "do direito da pessoa do inventor para o direito da sociedade investidora." Essa mudança de paradigma já pode ser considerada preocupante, na medida em que a perspectiva do investimento não contém nenhuma dimensão ética ou humana. Compensação pelo investimento não é sistematicamente sinônimo de progresso, e como relembra a Prof. Remiche, “acentuar o investimento ou mesmo para tirar dele o menor e mais próximo elemento - significa incitar a pesquisa e o investimento somente onde eles são os mais lucrativos e custo-efetivos!” (p. 128). O interesse público não pode ser reduzido ao interesse econômico; a justificação social para a propriedade intelectual é maior e deveria levar em consideração certos valores fundamentais.

${ }^{4}$ C.J. Craig, "Locke, Labour and Limiting the Author's Right: A Warning against a Lockean Approach to Copyright Law”, 28 Queen's L.J. 1 (2002), p. 14-15.

${ }^{5}$ Sobre esse retórica, ver geralmente: P.L. Loughlan, “'You Wouldn’t Steal a Car...' Intellectual Property and the Language of Theft”, EIPR 401 (2007).

${ }^{6}$ OHIM Report, European Citizens and Intellectual Property: Perception, Awareness and Behaviour, supra nota 2, p. 55.

${ }^{7}$ Mais sobre essa crise, ver e.g.:N. Kroes, Vice-Presidente da Comissão Européia responsável pela Agenda Digital (9 de Fevereiro de 2010 até $1^{\circ}$ de novembro de 2014), "Nosso mercado comum está gritando pela reforma do direito de autor", em discurso proferido na abertura do "Information Influx", no $25^{\circ}$ aniversário da Conferência Internacional do Institute for Information Law (IViR), Amsterdã, em 2 de Julho de 2014 (European Commission - SPEECH/14/528): “Todos os dias cidadãos [...] através da EU violam a lei somente para fazer alguma coisa lugar-comum. E quem pode culpá-los quando essas leis são tão mal-adaptadas [...] A tecnologia se movimenta mais rápido do que a lei, particularmente na UE. Hoje,
} 
aos autores, o direito de autor vem sendo cada vez mais percebido como um impedimento ao processo criativo, como o sucesso dos chamados modelos de "conteúdo aberto" claramente demonstram.

Esses desenvolvimentos atestam urgentemente a necessidade de repensar o direito de autor para adaptar suas regras a sua característica inicial dual: 1) um direito para assegurar e organizar participações culturais e o acesso aos trabalhos criativos (aspecto do acesso); e 2) a garantia de que os criadores participem justamente dos frutos da exploração econômica de seus trabalhos (aspecto da proteção). Evitar a privatização da informação ${ }^{8}$ pelo direito de autor e assegurar que os bens culturais ainda estejam disponíveis para futuras inovações pode significar a necessidade de (re)conceber o direito de autor como um direito ao acesso ${ }^{9}$ e não como um direito de proibir, desse modo enfatizando a natureza inclusiva e não exclusiva da proteção do direito de autor. ${ }^{10}$

Antes de entrar nas consequências de tal entendimento para a formação e aplicação do direito de autor(II), será necessário analisar primeiro as relações subjacentes, geralmente negligenciadas, da natureza do direito de autor como um “direito ao acesso” (I).

I. Racionalidades para conceber o direito de autor como um "direito ao acesso"

A. A função social do direito de autor e o seu vínculo filosófico ao interesse geral

Mesmo que as demandas de acesso ao direito de autor tenham sido somente feitas em um período relativamente curto, a ideia não é completamente nova. Já no século XIII, o teólogo

a moldura do direito de autor é fragmentada, inflexível, e na maioria das vezes irrelevante. Ele deveria ser um estimulante à abertura, inovação e criatividade; não uma ferramenta para obstrução, limitação e controle.”

${ }^{8}$ Mais sobre essa tendência, ver:C. Geiger, "Flexibilising Copyright - Remedies to the Privatisation of Information by Copyright Law”, 39(2) IIC 178 (2008).

${ }^{9} \mathrm{O}$ termo "direito ao acesso" no contexto desse artigo precisa ser claramente diferenciado de seu passado, de um entendimento diametralmente oposto. Com efeito, o termo "direito ao acesso" vem sendo usado em trabalhos acadêmicos prévios para descrever o direito de controle, e mesmo o direito de proibir o acesso aos trabalhos protegidos pelo direito de autor que resultem de medidas de proteção técnicas (technical protection measures - TPM) e a sua proteção legal. Ver e.g.:J.C. Ginsburg, "From Having Copies to Experiencing Works: The Development of an Access Right in U.S. Copyright Law", 50 Journal of the Copyright Society of the USA 113 (2003); T. Hoeren, "Access Right as a Postmodern Symbol of Copyright Deconstruction?”, in: J.C. Ginsburg and J.B. Besek (eds.), Adjuncts and Alternatives to Copyright, Actes du Congrès de l'ALAI 2001 (New-York, Kernochan Center for Law Media and the Arts, 2002), p. 360; T. Heide, “Copyright in the E.U. and the United States: What 'Access Right'?”, EIPR 476 (2001); S. Olswang, “Access right: An Evolutionary Path for Copyright in the Digital Era?”, EIPR 215 (1995).

${ }^{10}$ Considerando a ideia de inclusividade na PI, ver também: G. van Overwalle, "Smart Innovation and Inclusive Patents for Sustainable Food and Health Care: Redefining the Europe 2020 objectives”, in: C. Geiger (ed.), Constructing European Intellectual Property: Achievements and New Perspectives (EIPIN Series, Vol. 1, Cheltenham, UK / Northampton, MA, Edward Elgar, 2013); S. Dusollier, "Du gratuit au non-exclusif: Les nouvelles teintes de la propriété intellectuelle", in: Vers une rénovation de la propriété intellectuelle?, 30e anniversaire de l'IRPI (Paris, Litec, 2014), p. 29. 
e filósofo Tomás de Aquino expressava a ideia de que o direito positivo (jus positivum) poderia somente ser considerado como justo e legítimo na medida em que visasse ao bem estar geral; em outras palavras, se esse direito cumprisse com a sua "função social". Essa ideia foi reiterada por muitos outros filósofos do direito. ${ }^{11}$ Ela foi primeiramente confinada ao contexto do direito privado em geral (1) e depois estendida mais especificamente para a esfera da propriedade intelectual (2).

1. A função social do direito

Balanceamento é o conceito chave que subjaz à função social. O direito é uma questão de balanceamento. Não pode existir um direito absoluto que possa ser exercido de uma maneira completamente auto refletida sem consideração para com as consequências que esse exercício envolve. Como foi colocado perspicazmente por Du Pasquier, “o papel da lei é assegurar a coexistência pacífica do agrupamento humano ou, como geralmente dito, para harmonizar a atividade dos membros de uma sociedade. Em uma palavra, é a base da ordem social, que somente poderia ser atingida por um balanceamento entre interesses opostos.”12

Na França, essa ideia foi desenvolvida em 1930 por Louis Josserand. No que concerne ao direito de propriedade, ele escreveu que "não há necessidade de investigar mais profundamente para notar que esse direito que se clama como ilimitado envolve, acima de todos os ramos do direito estatal, uma multiplicidade de obstáculos, barreiras e fronteiras que constringem seu movimento e opõe-se a sua expansão”. Ele também arrematou: “isso é infortunado, pois se esse direito tirânico fosse deixado a si mesmo, a sua natureza específica, ele iria acabar por invadir a tudo e a se autodestruir". ${ }^{13}$ No campo do direito contratual, esse conceito vem sendo recentemente desenvolvido por acadêmicos do direito. Denis Mazeaud, por

\footnotetext{
${ }^{11}$ Para mais, ver: C. Geiger, "The Social Function of Intellectual Property Rights, Or how Ethics can Influence the Shape and Use of IP law", in: G.B. Dinwoodie (ed.), Intellectual Property Law: Methods and Perspectives (Cheltenham, UK/Northampton, MA, Edward Elgar, 2014), p. 153.

${ }^{12} \mathrm{C}$. Du Pasquier, Introduction à la théorie générale et à la philosophie du Droit (4th ed., Neuchâtel/Paris, Delachaux et Nestlé, 1967), p. 19. Ver tambémJ.H. Drake, prefácio editorial de R. von Ihering, Der Zweck im Recht ["O Direito como meios a um Fim”, traduzido no Brasil como "A Finalidade do Direito”] (Boston, Boston Book Company, 1913), p. 188: “ A lei não é a maior coisa no mundo, não é um fim em si mesmo; mas somente os meios para um fim; o propósito e o ser da existência da sociedade”. ${ }^{13}$ L. Josserand, De l'esprit des droits et de leur relativité (2nd ed., Paris, Dalloz, 1939, re-editado em 2006), p. 16.
} 
exemplo, advoga “o reconhecimento definitivo do 'princípio da lealdade, solidariedade e fraternidade’ como o principal princípio e guia do direito contratual contemporâneo”. ${ }^{14}$

Na Alemanha, a teoria da função social do direito privado (Sozialbindung des Privatrechts $)^{15}$ se tornou aparente no final do século XIX, tornando-se subsequentemente um princípio fundamental do direito privado alemão. ${ }^{16}$ Essa teoria insiste que os direitos privados são socialmente constritos. Isso sublinha a natureza social do sistema social e a função do direito privado, que é regular a relação entre indivíduos em uma sociedade. A função do sistema legal é então encontrar um compromisso entre os interesses dos indivíduos e os interesses da comunidade. Ela deve, por um lado, garantir a concessão de direitos subjetivos aos indivíduos e, por outro lado, garantir que esses direitos sejam compatíveis com os direitos do restante da comunidade. Os direitos dos indivíduos não são vistos como absolutos, mas direitos limitados em termos sociais. Além disso, essa teoria é aplicada por meio de uma prática judicial extremamente rica desenvolvida na base do artigo 242 do Código Civil alemão, no que diz respeito à boa-fé - uma cláusula geral, que na mão dos juízes alemães, tornou-se verdadeiramente um instrumento de balanceamento. ${ }^{17}$

\section{A função social do direito de autor e o interesse geral}

A ideia de que o direito de autor deve servir a uma função social tem sua origem no Iluminismo. ${ }^{18}$ Ela supõe que a propriedade intelectual é um produto ou tipo de "contrato social” entre o autor e a sociedade. ${ }^{19}$ De acordo com esse conceito, o direito de autor é justificado porque encoraja a criatividade. A sociedade tem necessidade de produções intelectuais para assegurar o desenvolvimento do progresso cultural, econômico, tecnológico e social, de maneira que concede ao autor uma recompensa na forma de um direito de propriedade intelectual, que o permite explorá-lo e tirar benefícios. Em troca, o autor, ao tornar acessível ao público sua criação, enriquece a comunidade. A lei é assim “condicionada” a atingir certos objetivos e seu

\footnotetext{
${ }^{14}$ D. Mazeaud, “Loyauté, solidarité, fraternité: la nouvelle devise contractuelle?”, in: L'avenir du droit, Mélanges en hommage à François Terré (Paris, Dalloz/PUF/Éditions du Jurisclasseur, 1999), p. 603.

${ }^{15}$ Literalmente traduzido, "os limites sociais do direito privado".

${ }^{16}$ O. Von Gierke, Die soziale Aufgabe des Privatrechts (Berlin, 1889; republicado por Klosterman, Frankfurt em 1943); J. Kohler, Das Autorrecht, eine zivilrechtliche Abhandlung (Verlag von G. Fischer, Jena, 1880), p. 41. Sobre essa teoria, ver mais recentemente T. Repgen, Die soziale Aufgabe des Privatrechts: eine Grundfrage in Wissenschaft und Kodifikation am Ende des 19. Jahrhundert (Tübingen, Mohr Siebeck, 2001).

${ }^{17}$ W.F. Ebke and B.M. Steinhauer, “The Doctrine of Good Faith in German Contract Law”, in: J. Beatson and D. Friedman (eds.), Good Faith and Fault in Contract Law (Oxford/ New York, Clarendon Press/Oxford University Press, 1997), p. 171.

${ }^{18}$ Ver, pro exemplo: A. Strowel, Droit d'auteur et copyright, Divergences et Convergences (Paris/ Brussels, Bruylant/ LGDJ, 1993), p. 86 et seq.; C. Geiger, Droit d'auteur et droit du public à l'information (Litec, Paris, 2004), p. 27 et seq.; "Copyright and Free Access to Information, For a Fair Balance of Interests in a Globalised World”, EIPR 366 (2006).

${ }^{19}$ Para mais detalhes, ver: C. Geiger, Droit d'auteur et droit du public à l'information, id., p. 27 et seq.
} 
uso pode ser (ao contrário, deve ser) mesurado à luz dos resultados obtidos. Esse foco particular nos interesses da sociedade levou logo com que vários acadêmicos alemães expandissem a teoria da função social aos direitos de propriedade intelectual. ${ }^{20}$ Julius Kopsh, já em 1920, invocava a ideia de uma função social “alongada” em relação à propriedade Intelectual. ${ }^{21}$

Um aspecto chave que deriva da função social é que os objetivos e as condições do direito de autor têm que ser sempre examinados à luz do interesse da sociedade e do interesse geral. Todavia, o que é exatamente o interesse geral? Na maior parte do tempo essa noção é intimamente relacionada às doutrinas utilitárias, mas, filosoficamente, existem várias versões diferentes do Utilitarismo. ${ }^{22}$ Mireille Buydens identifica três diferentes conceitos filosóficos. ${ }^{23} \mathrm{Em}$ um entendimento inicial, o interesse geral seria o interesse da Nação/Estado (Aristóteles, Hegel, Fichte) ${ }^{24}$ : qualquer coisa que o Estado defina como o interesse comum deve ser refletido na lei. Em uma segunda interpretação, a noção é entendida em seu sentido completamente oposto: o interesse geral é definido de acordo com os interesses particulares do indivíduo (Bentham, Adam Smith, John Stuart Mill). ${ }^{25} \mathrm{O}$ interesse geral seria aquele que maximiza os benefícios da maioria dos indivíduos. A terceira noção é inspirada no Cristianismo. O interesse geral é definido com o "bem da humanidade" (Tomás de Aquino, Hume); ${ }^{26}$ a referência sendo o ser humano. O papal da sociedade é definido como uma moldura para o desenvolvimento humano e a felicidade, de acordo com valores humanos universais, incluindo os benefícios materiais, como coesão social, solidariedade, educação, saúde, cultura, desenvolvimento sustentável, etc. Esse interesse geral deve se originar do "humano" e deve ser aplicado pelos legisladores. A vinculação aos direitos fundamentais é aqui facilmente realizada e, portanto, não é surpreendente encontrar os direitos fundamentais e as obrigações do direito constitucional entre a segunda categoria de racionalidades para o direito de autor como um “direito ao acesso".

B. O Direito de autor pelas lentes dos direitos fundamentais internacionais e a lei doméstica constitucional

\footnotetext{
${ }^{20}$ J. Kohler, Das Autorrecht, eine zivilrechtliche Abhandlung, supra nota 16, p. 40; E. Riezler, Deutsches Urheber- und Erfinderrecht (Munich/ Berlin, Schweitzer, 1909), p. 430.

${ }^{21}$ J. Kopsch, “Zur Frage der gesetzlichen Lizenz”, (1) ArchFunkR 201 (1928).

${ }^{22}$ Para uma análise fascinante no contexto da propriedade intelectual, ver M. Buydens, La propriété intellectuelle, Evolution historique et philosophique (Bruxelles, Bruylant, 2012), p. 351.

${ }^{23} \mathrm{M}$. Buydens, "L’intérêt général, une notion protéiforme", in: M. Buydens and S. Dusollier (eds.), L'intérêt général et l'accès à l'information en propriété intellectuelle (Brussels, Bruylant, 2008), p. 1.

${ }^{24}$ Id., p. 8 et seq.

${ }^{25}$ Id., p. 22 et seq.

${ }^{26} I d .$, p. 37 et seq.
} 
As racionalidades do direito que subjazem à proteção da PI podem ser vistas em inúmeros tratados internacionais e regionais de direitos fundamentais e em constituições nacionais no mundo. Isso é feito, primeiramente, pela incorporação de $\operatorname{certos}^{27}$ aspectos do direito de autor no direito universalmente reconhecido à cultura e à ciência ${ }^{28}(1)$. Em segundo lugar, o aspecto do acesso ao direito de autor pode ser traçado, igualmente, em fundações “expressivas” da PI e internacionalmente vinculadas, de acordo com as quais o direito de autor pode ser visto como uma exceção ao direito genérico de se expressar livremente, receber e transmitir informações ${ }^{29}$ (2). Finalmente, a inclusão do direito de autor como propriedade no nível constitucional ${ }^{30}$ de uma maneira geral garante que a função social da propriedade seja estendida à propriedade intelectual(3).

1. O Direito de autor como um direito que garante o acesso à cultura e à ciência

O melhor exemplo de uma estrutura de salvaguarda ao acesso e à proteção ao direito de autor é oferecido pelo artigo $27^{\circ}$ da Declaração Universal dos Direitos do Homem (DUDH). ${ }^{31}$ De acordo com esse parágrafo, todo mundo tem o direito de "tomar parte livremente na vida cultural da comunidade, de fruir as artes e de participar no progresso científico e nos benefícios que deste resultam,” ao mesmo tempo em que, de acordo com o segundo parágrafo da mesma provisão, todo mundo tem direito à proteção dos interesses morais e materiais resultantes da produção literária, científica e artística de sua autoria. ${ }^{32}$ Embora seja verdade que a DUDH não tenha um efeito diretamente vinculante, o mesmo não pode ser dito do artigo 15(1) do Pacto Internacional sobre os Direitos Econômicos, Sociais e Culturais (PIDESC), ${ }^{33}$ adotando

\footnotetext{
${ }^{27}$ Considerando a distinção que existe entre o standard dos direitos de PI e os direitos fundamentais que são concendidos aos criadores, de acordo com o direito à cultura e à ciênca, ver:UN Committee on Economic, Social and Cultural Rights (CESCR), General Comment No. 17: The Right of Everyone to Benefit from the Protection of the Moral and Material Interests Resulting from any Scientific, Literary or Artistic Production of Which He or She is the Author (Art. 15, Para. 1 (c) of the Covenant), 12 de janeiro de 2006, E/C.12/GC/17.

${ }^{28}$ Ver, no nível internacional, o artigo 27 da Declaração Universal dos Direitos do Homem - DHDH (Universal Declaration of Human Rights - UDHR) e o artigo 15 do Pacto Internacional sobre Direitos Econômicos, Sociais e Culturais - PIDESC (International Covenant on Economic, Social and Cultural Rights - ICESCR).

${ }^{29}$ Ver o artigo 19 da DHDH e o artigo 19 do Pacto Internacional sobre Direitos Civis e Políticos - PIDCP (International Covenant on Civil and Political Rights - ICCPR).

${ }^{30}$ No nível internacional, ver o artigo 17 da DUDH. Note, todavia, que nem o PIDESC, tampouco o PIDCP, dá corpo a uma garantia similar de propriedade no catálogo dos direitos fundamentais.

${ }^{31}$ Assembléia Geral das Nações Unidas, Declaração Universal dos Direitos do Homem, 10 de dezembro de 1948, Resolução 227 A, UN Doc. A/810.

${ }^{32}$ Analisando o artigo $27^{\circ}$ da DHDH, ver:E. Stamatopoulou, Cultural Rights in International Law: Article 27 of the Universal Declaration of Human Rights and Beyond (Martinus Nijhoff Publishers, Leiden/Boston, 2007), p. 110.

${ }^{33}$ Assembléia Geral das Nações Unidas, Pacto Internacional dos Direitos Econômicos, Sociais e Culturais, 16 de dezembro de 1966, 993 UNTS 3.
} 
as palavras da DUDH quase que literalmente. ${ }^{34}$ No nível regional, o direito de autor é similarmente concebido como permitindo o acesso à ciência e à cultura, tendo em vista o artigo 14 do Protocolo Adicional à Convenção Americana sobre Direitos Humanos(PACADH) ${ }^{35}$ e o artigo 13 da Declaração Americana dos Direitos e Deveres do Homem ${ }^{36}$ - essa última, na realidade, precursora da DUDH. ${ }^{37}$

As fundações clássicas da PI são colocadas em uma balança estável por meio desses instrumentos internacionais de direitos fundamentais: de um lado, o reconhecimento do direito natural por meio de um direito de exploração econômica e um "droit moral" ao criador; por outro lado, a fundação utilitária, uma vez que esse reconhecimento tem como finalidade a promoção da variedade intelectual e a disseminação da cultura e da ciência. ${ }^{38}$ Além disso, tanto a DUDH e o PIDESC enfatizam a ligação ao "autor", nomeadamente o criador, fazendo referência também às palavras "ele” e "todo mundo", dessa forma excluindo a proteção às pessoas jurídicas do nível dos direitos humanos. ${ }^{39}$

No que diz respeito ao nível constitucional doméstico, um número impressionante de instrumentos primários se espelham na DUDH e no PIDESC para salvaguardar o direito dos criadores tendo em vista o escopo dos direitos à cultura e à ciência. ${ }^{40} \mathrm{~A}$ maioria dessas cláusulas

\footnotetext{
${ }^{34}$ Para uma maior discussão, ver: C. Sganga, "Right to Culture and Copyright: Participation and Access”, em breve em: C. Geiger (ed.), Research Handbook on Human Rights and Intellectual Property (Cheltenham, UK/ Northampton, MA, Edward Elgar, 2015); L. Shaver e C. Sganga, "The Right to Take Part in Cultural Life: on Copyright and Human Rights”, 27 Wisconsin International Law Journal 637 (Winter 2010); L. Shaver, “The Right to Science and Culture”, (1) Wisconsin Law Review 121 (2010).

${ }^{35}$ Organização dos Estados Americanos, Protocolo Adicional à Convenção Americana sobre Direitos Humanos em Matéria de Direitos Econômicos, Sociais e Culturais "Protocolo de San Salvador”, 17 de novembro de 1988, OASTSNo. 69.

${ }^{36}$ Comissão Inter-Americana sobre Direitos Humanos, Declaração Americana dos Direitos e Deveres do Homem, 2 de maio de 1948, OAS Res. XXX, adotada pela Nona Conferência Internacional Americana, Bogotá, 1948, reimpressa em Basic Documents Pertaining to Human Rights in the Inter-American System, OAS/Ser.L/V/I.4 Rev. 9 (2003).

${ }^{37}$ Desde que as provisões da DHDH foram discutidas, o PIDESC, o PACADH e a Declaração Americana correspondem proximamente uma a outra. Esse artigo aborda somente as provisões da DUDH e do PIDESC como instrumentos de cobertura internacional.

${ }^{38}$ Para uma maior discussão sobre essas fundações clássicas da PI, ver: C. Geiger, “'Constitutionalising’ Intellectual Property Law?, The Influence of Fundamental Rights on Intellectual Property in Europe”, 37(4) IIC 371 (2006), p. 377 et seq.

${ }^{39}$ Ver CESCR, General Comment No. 17, supra nota 27, para. 7.

${ }^{40}$ Para exemplos de tais provisões constitucionais, ver: artigo 54(3) da Constituição da Bulgária de 1991; artigo 69 da Constituição da Croácia de 1990; artigo 34(1) da Carta Fundamental dos Direitos Checos de 1993; artigo 113 da Constituição da República da Letônia de 1922; artigo 42 da Constituição da Lituânia de 1992; artigo 43(1) da Constituição eslovaca de 1992; artigo 42 da Constituição da República Portuguesa de 1976; Artigo 36 da Constituição da Armênia de 1995; artigo 44(1) da Constituição da Federação Russa de 1993; artigo 73(2) da Constituição da Sérvia de 2006; artigo 58 da Constituição albanesa de 1998; artigo 64 da Constituição da Turquia de 1982; artigo 2(8) da Constituição do Peru de1993; artigo 98 da Constituição da Venezuela de 1999; artigo I, seção 8a , Cláusula 8 a da Constituição dos Estados Unidos da América de 1787; artigos 125 e 127 da Constituição da Nicarágua 1986; artigo 29 da Constituição do Congo de 2002; artigo 46 da Constituição da República Democrática do Congo de
} 
são caracterizadas por palavras de balanceamento, referindo-se diretamente à dimensão do interesse público no direito de autor. Para dar apenas alguns exemplos: o artigo 46 da Constituição da Lituânia de 1992 assegura que o Estado deve "suportar a cultura e a ciência" enquanto "defendendo e protegendo os interesses materiais e espirituais do autor que são

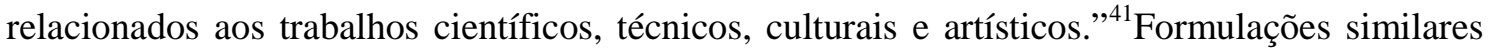
são adotadas por outras Constituições no mundo inteiro, incluindo o artigo 73 da Constituição da Sérvia de 2006, artigo 98 da Constituição da Venezuela de 1998, artigo 46 da Constituição da República Democrática do Congo de 2006 e o artigo 40 da Constituição do Tajiquistão de 1994. Todavia, talvez a provisão constitucional mais famosa, explicitamente referindo-se ao interesse geral como um objetivo legislativo para o direito de autor, seja 0 artigo $1^{0}$, seção $8^{a}$, cláusula $8^{\mathrm{a}}$ da Constituição dos Estados Unidos de 1787². “o Congresso deverá ter o poder [...] para promover o progresso da ciência e das artes úteis, ao assegurar aos autores e aos inventores, por um tempo limitado, os direitos exclusivos em seus respectivos escritos e descobertas". ${ }^{43}$

As considerações do interesse público que subjazem à concessão da proteção são salientes: os direitos exclusivos são conferidos contanto e na medida em que eles facilitem o progresso cultural. Os interesses da sociedade não são somente a razão para a concessão da proteção como também a razão para limitá-la. Essa premissa foi mais adiante interpretada e complementada pela prática judicial estabelecida pela Suprema Corte Norte-Americana. Por exemplo, uma decisão que data de 1932 estabeleceu que o "único interesse dos Estados Unidos e o objetivo primário na concessão de um monopólio subjazem nos benefícios derivados do trabalho dos autores pelo público". ${ }^{44}$ Ademais, a Cláusula do Progresso expressamente se refere

2006; artigo 94 da Constituição de Moçambique de 2004; artigo 26 da Constituição de Madagascar de 1992; artigo 47 da Constituição do Afeganistão de 2004; artigo 49 da Constituição do Quirguistão de 2010; artigo 16 da Constituição da Mongólia de 1992; artigo 22 da Constituição da República da Coréia de 1948; artigo 40 da Constituição do Tajiquistão de 1994; artigo 60 da Constituição do Vietnã de 1992; parte $9^{a}$, seção $86^{a}$ da Constituição da Tailândia de 2007. Para uma discussão mais aprofundada, ver:C. Geiger, "Implementing Intellectual Property Provisions in Human Rights Instruments: Towards a New Social Contract for the Protection of Intangibles", Max Planck Institute for Innovation and Competition Research Paper No. 14-10, breve in: C. Geiger (ed.), Research Handbook on Human Rights and Intellectual Property, supra nota 34.

${ }^{41}$ Destaques em itálico. Para uma excelente análise da Constituição da Lituânia e a interpretação do artigo 42, ver:V. Mizaras, "Issues of Intellectual Property Law in the Jurisprudence of the Constitutional Court of the Republic of Lithuania”, 19(3) Jurisprudence (2012).

${ }^{42}$ A chamada "cláusula do progresso".

${ }^{43}$ Ênfase em itálico.

${ }^{44}$ Fox Film Corp. v. Doyal, 286 U.S. 123, 127 (1932). Muitos casos reiteraram o interesse público e o bem público. Ver, por exemplo, Fogerty v. Fantasy, Inc., 510 U.S. 517, 526 (1994): "Nós temos amiúde reconhecido que os privilégios do monopólio que o Congresso autorizou, enquanto intencionados a motivar à criatividade dos autores e inventores pela provisão de uma recompensa especial', são limitados em sua natureza e devem ultimamente servir ao bem público'” (referindo-se "a balizada decisão em Sony Corp. of America v. Universal City Studios, Inc., 464 U.S. 417, 429 (1984), ênfase em itálico). Ver também Harper \& Row, Publishers, Inc. v. Nation Enterprises, 471 U.S. 539, 558 (1985): “A filosofia econômica por trás da cláusula autorizando o Congresso a conceder patentes e direitos de autor é a 
ISSN ELETRÔNICO 2316-8080

COPYRIGHT COMME UN DROIT A GARANTIR L'ACCES A LA PARTICIPATION CULTURELLE PAR LA

PROTECTION DES INTERETS DES CREATEURS

aos "autores" como beneficiários da proteção do direito de autor, assim reforçando, no nível constitucional, o papel primário do criador.

2. O direito de autor como uma exceção à liberdade de expressão

A percepção constitucional do direito de autor como parte integral do direito à liberdade de expressão e à informação está na sua capacidade direta de permitir o acesso à cultura.

Desde a sua concepção, o direito de autor manteve relações próximas com a liberdade de expressão e seu corolário: o direito do público de receber e comunicar informações. ${ }^{45} \mathrm{Com}$ efeito, o acesso à informação e ao direito de autor converge completamente em relação aos princípios e racionalidades envolvidas. ${ }^{46}$

Uma boa ilustração dessa convergência é o artigo 20 da Constituição espanhola de 1978, em que a proteção da PI é colocada ao lado do direito à liberdade de expressão e à informação (parágrafo 1(b)). ${ }^{47}$ Como explica sucintamente F. Bondia em seu comentário, “a liberdade de expressão pertence à propriedade intelectual, já que a sua falta mata a criatividade artística, pesquisa científica, bem como a busca filosófica pela verdade. Além disso, a propriedade intelectual é o leito do rio ou o canal pelo qual a liberdade de expressão passa, e é perfeitamente compreensível em nossa Constituição quando ela reagrupa ambos os direitos no mesmo artigo legal..." ${ }^{48}$ Com efeito, alguém pode inferir que o objetivo do artigo 20 da Constituição espanhola é, ao menos em parte, garantir a liberdade de expressão e o direito do público à informação - uma lógica que poderia ser traçada ainda mais no artigo 15(e) da Constituição da Libéria de 1984, quando ela se refere "ao aspecto comercial da expressão [...] na infração do direito de autor”, e o artigo 13 da Constituição Centro Africana de 2004,

convicção de que o encorajamento do esforço de um indivíduo pelo ganho pessoal é a melhor forma de avançar o interesse do bem-estar social pelo talento dos autores e inventores na "ciência e artes úteis" (citando Mazer v. Stein, 347 U.S. 201, 219 (1954), ênfase em itálico); N.Y. Times Co. v. Tasini, 533 U.S. 483, 524 (2001), n.20 (J. Stevens, dissentindo): “A lei do direito de autor não é uma apólice de seguro para os autores, mas um balanceamento cuidadosamente atingido entre a necessidade de criar incentivos para os autores e os interesses da sociedade na grande acessibilidade às ideias” (ênfase em itálico).

${ }^{45}$ Ver: C. Geiger, Droit d'auteur et droit du public à l'information, supra nota 18, at 27 et seq.

${ }^{46} \mathrm{Em}$ relação à natureza dual do direito à liberdade de expressão, ver o documento recentemente publicado pelo Freedom of Expression on the Internet Initiative of the Center for Studies on Freedom of Expression and Access to Information, Freedom of Expression versus freedom of expression: copyright protection invokes internal tension (Universidade de Palermo, 2013).

${ }^{47}$ Para uma maior discussão, ver: J.M. Otero, "La protección constitucional del derecho de autor: Análisis del artículo 20.1 b/ de la Constitución española de 1978”, Part 2 La Ley 370 (1986).

${ }^{48}$ F. Bondia, Propiedad intellectual: su significado en la Sociedad de la Información (Trivium, Madrid, 1988), pp. 94 e 105, citado por J. Rodriguez, “A Historical Approach to the Current Copyright Law in Spain”, 28(7) EIPR 389 (2006), p. 393. 
incorporando a proteção “da liberdade de criação intelectual, artística e cultural” no direito maior à liberdade de expressão e informação.

Além das Constituições domésticas, a Convenção Européia dos Direitos do Homem $(\mathrm{CEDH})$ codifica o princípio da liberdade de expressão e comunicação no artigo $10(1)^{49}$ enquanto que o artigo 10(2) estipula restrições para a proteção dos direitos de outros, o que inclui o direito dos criadores. ${ }^{50}$

O reconhecimento do direito dos criadores como uma exceção à regra geral da proteção à liberdade de expressão foi evidenciado pelos recentes casos da Corte Européia dos Direitos do Homem (CtEDH), o corpo encarregado de interpretar a CEDH. ${ }^{51}$ Em particular, duas importantes decisões da Corte adotadas em 2013, Ashby Donald"52 e o "O Pirate Bay,”, claramente demonstraram uma grande mudança de perspectiva do direito de autor, tradicionalmente considerado imune a uma revisão externa operada pela liberdade de expressão. Nos dois casos, a CtEDH julgou que o uso de um trabalho protegido pelo direito de autor poderia ser considerado como uma exercício à liberdade de expressão, mesmo que o uso fosse ilegal e motivado pelo lucro. Desse modo, ao verificar se uma dada situação de interferência pode ser justificada em relação a outros direitos em conflito, a CtEDH avançou a ideia de que a liberdade de expressão tem que ser considerada como o ponto de início e que nenhuma resposta pré-determinada pode ser dada pelo direito de autor. ${ }^{54}$ Isso se alinha com o princípio da liberdade de "expressão-conforme", que postula que o direito exclusivo constitui uma exceção ao princípio maior da liberdade de uso. ${ }^{55}$

\footnotetext{
${ }^{49}$ Na UE, proteções análogas às garantias da liberdade de expressão são resguardadas pelo artigo 11 da Carta dos Direitos Fundamentais da UE, sendo seu escopo e significado os mesmos do artigo 10 da CEDH (vernota de Praesidium, Draft Charter of Fundamental Rights of the European Union, Text of the Explanations Relating to the Complete Text of the Charter as set out in CHARTE 4487/00 CONVENT 50 (Bruxelas, 2000), p. 13-14.

${ }^{50}$ Os casos em que o direito de autor foi considerado como satisfazendo a categoria do "direito de outros" no sentido do artigo 10(2) da CEDH, incluem: Corte Européia dos Direitos do Homem(CtEDH), Neij e Sunde Kolmisoppi v. Suécia (dec.), no. 40397/12, 19 de Fevereiro de 2013, não-reportado; CtEDH, Ashby Donald e outros v. França, no. 36769/08, 10 de Janeiro de 2013, não-reportado; ECommHR, Société Nationale de Programmes FRANCE 2 v. França (dec.), no. 30262/96, 15 de Janeiro 1997, não-reportado; ECommHR, N.V. Televizier v. Países Baixos, no. 2690/65, 3 de Outubro de 1968, não-reportado.

${ }^{51}$ Ver:C. Geiger and E. Izyumenko, "Copyright on the Human Rights' Trial: Redefining the Boundaries of Exclusivity Through Freedom of Expression”, 45(3) IIC 316 (2014).

${ }^{52} \mathrm{CtEDH}$, Ashby Donald e outros v. França, supra nota 50; 45(3) IIC 354 (2014); 4(1) Queen Mary Journal of Intellectual Property 95 (2014), comentários de P. Torremans.

${ }^{53} \mathrm{CtEDH}$, Neij e Sunde Kolmisoppi v. Suécia (dec.), supra nota 50; 44(6) IIC 724 (2013). Para um comentário, ver:J. Jones, "Internet Pirates Walk the Plank with Article 10 Kept at Bay: Neij and Sunde Kolmisoppi v Sweden”, 35(11) EIPR 695 (2013).

${ }^{54}$ Para um comentário conjunto de Ashby Donald e "O Pirate Bay", ver:C. Geiger and E. Izyumenko, "Copyright on the Human Rights' Trial", supra nota 51. Ver tambémD. Voorhoof, "Freedom of Expression and the Right to Information: Implications for Copyright”, em breve in: C. Geiger (ed.), Research Handbook on Human Rights and Intellectual Property, supra nota 34.

${ }^{55}$ C. Geiger, "Fundamental Rights, a Safeguard for the Coherence of Intellectual Property Law?”, 35(3) IIC 268 (2004), p. 272, estatuindo que os "direitos de propriedade intelectual constituem ilhas de exclusividade em um oceano de liberdade”. Mais sobre as importantes implicações do direito à liberdade de expressão para o direito de autor, ver: D. Voorhoof, "Freedom of Expression and the Right to
} 
3. O direito de autor como um direito de propriedade - a extensão da função social

Existe, para além do artigo 10, outra provisão na CEDH que pode auxiliar na compreensão do vínculo entre a proteção ao direito de autor e às justificações de interesse público. $\mathrm{O}$ artigo $1^{\circ}$ do primeiro protocolo à $\mathrm{CEDH}$ (garantindo a proteção à propriedade) se estende, de fato, na ausência de uma cláusula específica de PI na própria Convenção, à proteção dos direitos de propriedade intelectual. ${ }^{56}$

A inclusão da proteção da propriedade intelectual no patamar constitucional é importante, uma vez que estende à propriedade intelectual a função social da propriedade. Com efeito, o direito de propriedade protegido pela Convenção é inerentemente limitado por sua função social. ${ }^{57} \mathrm{O}$ parágrafo primeiro do artigo $1^{\circ}$ do Primeiro Protocolo adicional à CEDH prevê a possibilidade de restrições ao direito de propriedade "no interesse público”, enquanto que o parágrafo segundo da mesma provisão permite aos Estados “... pôr em vigor as leis que julguem necessárias para a regulamentação do uso dos bens, de acordo com o interesse geral..."58

Information”, id.; C. Geiger and E. Izyumenko, “Copyright on the Human Rights' Trial”, supra nota 51. Em relação ao direito de marcas, ver M. Senftleben, "Free Signs and Free Use: How to Offer Room for Freedom of Expression within the Trademark System”, e para nomes de domínio, ver J.D. Lipton, "Free Speech and Other Human Rights in ICANN's New Generic Top Level Domain Process: Debating Topdown versus Bottom-up Protections”, ambos em Research Handbook on Human Rights and Intellectual Property, supra nota 34.

${ }^{56} \mathrm{~A}$ jurisprudência da CtEDH, considerando diferentes direitos de propriedade intelectual, ligou-os à provisão relativa ao direito de propriedade na Convenção. Ver, em relação ao direito de autor: CtEDH, Neij e Sunde Kolmisoppi v. Suéca (dec.), supra nota 50; CtEDH, Ashby Donald e outros v. França, supra nota 50; CtEDH, Balan v. Moldávia, no. 19247/03, 29 de janeiro de 2008, não-reportado; CtEDH, Melnychuk v. Ucrânia (dec.), no. 28743/03, 5 de julho de 2005, Reports of Judgments and Decisions 2005-IX; CtEDH, Dima v. Romênia (dec.), no. 58472/00, 26 de maio de 2005, não-reportado; ECommHR, Aral, Tekin e Aral v. Turquia (dec.), no. 24563/94, 14 de janeiro de 1998, não-reportado; ECommHR, A.D. v. Países-Baixos (dec.), no. 21962/93, 11 de janeiro de 1994, não-reportado. No campo do direito das marcas: CtEDH, Paeffgen Gmbh v. Alemanha (dec.), nos. 25379/04, 21688/05, 21722/05 e 21770/05, 18 de setembro de 2007, não-reportado; CtEDH, Anheuser-Busch Inc. v. Portugal [GC], no. 73049/01, 11 de janeiro de 2007, Reports of Judgments and Decisions 2007-I. No campo das patentes: ECommHR, Lenzing AG v. Reino Unido (dec.), no. 38817/97, 9 de setembro de 1998, não-reportado; ECommHR, Smith Kline \& French Lab. Ltd. v. Países-Baixos (dec.), no. 12633/87, 4 de outubro de 1990, Decisions and Reports 66, p. 70. Para uma análise detalhada da jurisprudência da Corte em propriedade intelectual, ver: L.R. Helfer, "The New Innovation Frontier? Intellectual Property and the European Court of Human Rights", 49 Harvard International Law Journal 1 (2008); D.S. Welkowitz, "Privatazing Human Rights? Creating Intellectual Property Rights from Human Rights Principles”, 46 Akron Law Review 675 (2013).

${ }^{57}$ Para mais detalhes, ver: C. Geiger, “The Social Function of Intellectual Property Rights”, supra nota 11.

${ }^{58}$ Ênfase em itálico. 
Contrariamente a CEDH, outro instrumento principal dos direitos fundamentais, a Carta dos Direitos Fundamentais da União Européia (Carta da UE), dispõe explicitamente que a propriedade intelectual faz parte do catálogo dos direitos fundamentais. Em particular, enquanto o artigo 17 estipula o direito de propriedade em seu primeiro parágrafo, o segundo parágrafo dispõe de uma maneira um tanto lacônica que “é protegida a propriedade intelectual”59. Mesmo que a questão não seja isenta de considerável controvérsia, a cláusula precisa ser analisada tendo em vista a disposição em que ela foi incorporada. O artigo 17(1) da Carta da UE, em relação à garantia geral do direito de propriedade, salvaguarda seus limites sociais, reiterando que "a utilização dos bens pode ser regulamentada por lei na medida do necessário ao interesse geral." 60

A natureza limitada do direito de propriedade foi claramente visada pelas pessoas responsáveis por redigir os termos da CEDH e da Carta. Como os travaux préparatoires do Primeiro Protocolo adicional à CEDH demonstram, o novo paradigma da propriedade introduzido foi visto de uma natureza "relativa", ao contrário de um direito de natureza absoluta, no sentido compreendido pelo direito romano. ${ }^{61}$ Uma lógica similar, claramente excluindo uma concepção “absolutista” da PI e acompanhando os documentos preparatórios da Carta da UE, pode ser observada na cuidadosa especificação feita pelos legisladores de que "as garantias estipuladas no parágrafo primeiro [do artigo 17] deverão se aplicar como apropriadas à propriedade intelectual” e que "o sentido e o alcance do artigo 17 são os mesmos que aqueles garantidos pelo artigo $1^{\circ}$ do Primeiro Protocolo à CEDH., ${ }^{, 62} \mathrm{O}$ artigo $17(2)$ da Carta pode ser considerado como uma mera clarificação do artigo 17(1), o que impossibilitaria expandir a proteção da PI nessas bases.

Essa compreensão "restritiva” vem claramente acompanhando a jurisprudência do Tribunal de Justiça da União Europeia (TJUE).$^{63}$ De acordo com este, “importa referir que não

\footnotetext{
${ }^{59}$ Para mais informações, ver:C. Geiger, "Intellectual Property Shall be Protected!? Article 17(2) of the Charter of Fundamental Rights of the European Union: a Mysterious Provision with an Unclear Scope”, 31(3) EIPR 113 (2009); “Intellectual 'Property' after the Treaty of Lisbon, Towards a Different Approach in the New European Legal Order?”, 32(6) EIPR 255 (2010). Ver também: J. Griffiths e L. McDonagh, "Fundamental Rights and European Intellectual Property Law - The Case of Art 17(2) of the EU Charter”, in: C. Geiger (ed.), Constructing European Intellectual Property, supra nota 10, p. 75.

${ }^{60}$ Ênfase em itálico.

${ }^{61}$ Conselho da Europa, Preparatory work on Article 1 of the First Protocol to the European Convention on Human Rights, CDH (76) 36, Strasbourg, 13 de Agosto de 1976 (ver, e.g., a apresentação do Sr. de la Vallée-Poussin (Bélgica), p. 12; considere, igualmente, o depoimento do Sr. Nally (Reino Unido) p. 16, de que "a base da luta da Europa para a sua sobrevivência é a luta pela subordinação do direito privado de propriedade às necessidades da comunidade”.

${ }^{62}$ Nota de Praesidium, Draft Charter of Fundamental Rights of the European Union, supra nota 49, p. 19-20.

${ }^{63}$ Ver, e.g. TJE, Caso C-275/06, Promusicae [2008], Julgamento do Tribunal (Grande Secção) de 29 de janeiro de 2008, paras. 65-68, ECR I-00271; TJE, Caso C-557/07, Tele2 [2009], Ordem do Tribunal (Oitava Secção) de 19 de fevereiro de 2009, paras. 28 e 29, ECR I-01227; TJEU, Caso C-461/10, Bonnier Audio e outros [2012], Julgamento do Tribunal (Terceira Secção) de 19 de Abril de 2012, para. 56, publicado eletronicamente em Repositório de Casos; TJEU, Caso C-145/10, Painer [2011], Julgamento
} 
decorre de forma alguma do artigo $17 .^{\circ}, \mathrm{n} .^{\circ}$ 2, da Carta que o direito de propriedade intelectual seja inviolável e que a sua proteção deva, portanto, ser assegurada de forma absoluta.” ${ }^{64}$ Ademais, para remover qualquer ambiguidade, em Lukas v. Petrus o TJUE se referiu diretamente ao artigo 17(1) da Carta da UE no contexto da propriedade intelectual, antes mesmo de discutir o artigo 17(2) - uma ilustração explícita por parte da Tribunal de que a cláusula da propriedade intelectual está ligada às palavras gerais do artigo 17(1). ${ }^{65}$

O direito de propriedade na Carta e na CEDH é considerado como possuindo fortes limites sociais e seu escopo de proteção é limitado em sua própria natureza, ${ }^{66}$ deixando aos Estados uma larga margem de apreciação para regular a propriedade. ${ }^{67}$ Isso significa que o direito de autor, da mesma forma que o direito de propriedade, pode ser limitado para salvaguardar o interesse público.

II. As consequências do direito de autor como um direito ao acesso para seu uso e formação

do Tribunal (Terceira Secção) de $1^{\circ}$ de dezembro de 2011, paras. 105 e 132, ECR I-12533; TJEU, Caso C-70/10, Scarlet Extended [2011], Julgamento do Tribunal (Terceira Seç̧ão) de 24 de novembro 2011, para. 53, ECR I-11959; TJEU, Caso C-360/10, SABAM v. Netlog [2012], Julgamento do Tribunal (Terceira Secção) de 16 de fevereiro de 2012, para. 51, publicado eletronicamente em Repositório de Casos; TJEU, Caso C-314/12, UPC Telekabel [2014], Julgamento do Tribunal (Quarta Secção) de 27 de março de 2014, para. 46, ainda não publicado; e TJEU, Caso C-201/13, Deckmyn [2014], Julgamento do Tribunal (Grande Secção) de 3 de setembro de 2014, paras. 26 e 27, ainda não publicado. Analisando alguns desses casos, ver:C. Geiger and F. Schönherr, "Limitations to Copyright in the Digital Age", in: A. Savin and J. Trzaskowski (eds.), Research Handbook on EU Internet Law (Cheltenham, UK / Northampton, MA, Edward Elgar, 2014), 110, e dos mesmos autores: "Defining the Scope of Protection of Copyright in the EU: The Need to Reconsider the Acquis Regarding Limitations and Exceptions", in: T. Synodinou (ed.), Codification of European Copyright Law, Challenges and Perspectives (Alphen aan den Rijn: Kluwer Law International, 2012), 142; J. Griffiths, "Constitutionalising or Harmonising? The Court of Justice, the Right to Property and European Copyright Law", 38 European Law Review 65 (2013); e, mais recentemente, European Copyright Society (ECS), "Limitations and Exceptions as Key Elements of the Legal Framework for Copyright in the European Union: Opinion on the Judgment of the CJEU in Case C-201/13 Deckmyn", $1^{\circ}$ de novembro de 2014, disponível em <http://infojustice.org/wpcontent/uploads/2014/11/Limitations-and-Exceptions-as-Key-Elements-of-the-Legal-Framework-for Copyright-in-the-EU.pdf> (acesso em 26 de novembro de 2014), breve em IIC 2005/1.

${ }^{64}$ TJEU, Caso C-314/12, UPC Telekabel [2014], id., para. 61; TJEU, Caso C-360/10, SABAM v. Netlog [2012], id., para. 41; TJEU, Caso C-70/10, Scarlet Extended [2011], id., para. 43 (ênfase em itálico).

${ }^{65}$ TJEU, Caso C-277/10, Martin Luksan v. Petrus van der Let [2012], Julgamento do Tribunal (Terceira Seç̧ão) de 9 de fevereiro de 2012, para. 68, ainda não publicado.

${ }^{66}$ Ver, nesse sentido, C. Calliess, "The Fundamental Right to Property", in: D. Ehlers (ed.), European Fundamental Rights and Freedoms (Berlin, De Gruyter, 2007), p. 456, estatuindo que a função social "serve como uma justificação para restrições impostas na utilização da propriedade".

${ }^{67}$ Pro exemplo, no caso Smith Kline (ECommHR, Smith Kline \& French Lab. Ltd. v. Países Baixos (dec.), supra nota 56), a Comissão Européia dos Direitos do Homem estatuiu que, de acordo com a lei holandesa, a concessão de uma licença compulsória para uma droga patenteada não era uma violação do artigo $1^{\circ}$ do Primeiro Protocolo. Ela considerou que a licença compulsória era legal e que perseguia o legítimo objetivo de encorajar o desenvolvimento tecnológico e econômico. 
A. A necessidade de assegurar o balanceamento de interesses no direito de autor: o contrato social implica em deveres para os autores e direitos para os usuários

Ao se admitir o propósito social da propriedade intelectual, e considerando que ela está ancorada nas obrigações dos direitos fundamentais, isso deve levar com que o legislador verifique se as regras do direito de autor realmente refletem esse aspecto e, em caso negativo, corrija-as. Como nota argutamente o professor Schricke, se as consequências culturais, econômicas e sociais não são devidamente levadas em consideração pelo direito de autor, alguém poderia começar por suspeitar se não deveria ser esperado da legislatura (e os juízes interpretando as provisões do direito de autor) maior atenção ao interesse geral em seu sentido positivo: o direito de autor deveria ser concebido de tal maneira a potencializar ao máximo o desenvolvimento do progresso intelectual, cultural e econômico. ${ }^{68}$ Primeiro, isso iria requer que o legislador justificasse convincentemente a concessão dos direitos de propriedade intelectual (o que é difícil, considerando que algumas regras são o resultado apenas de grupos de pressão), e o exercício concomitante de “auto-monitoramento”. Nesse sentido, considerando a função social em seu aspecto integral ao acesso, isso poderia implicar em um dever de demonstrar as razões pelas quais a legislação foi promulgada e que resultados podem ser obtidos, considerando dados confiáveis e estudos de impacto, tornando, dessa maneira, possível mesurar possíveis consequências da atividade legislativa. ${ }^{69}$ Isso teria um resultado muito importante, na medida em que o legislador teria a obrigação de justificar uma extensão do direito de propriedade intelectual.

Uma questão, então, surge: como obrigar a legislatura a respeitar o direito de autor como um direito ao acesso? Se o direito ao acesso à propriedade intelectual é alçado ao nível supra-legislativo esse poderia ser o caso. O problema é que na UE e alguns Estados Membros, diferentemente dos Estados Unidos, não existe nenhuma cláusula constitucional regulando o nível da atividade legislativa para a promulgação da propriedade intelectual. Todavia, como enfatizado acima, a propriedade intelectual foi alçada ao nível supra-legislativo no momento em que vinculada à proteção constitucional da propriedade, e esta pode ser objeto de restrições justificadas pelo interesse geral. Nesse espírito, o Tribunal Constitucional alemão decidiu claramente no contexto do direito de autor que a proteção aos direitos de propriedade intelectual

\footnotetext{
${ }^{68}$ G. Schricker, “Introduction”, in: G. Schricker (ed.), Urheberrecht Kommentar (2nd ed., Munich, Beck, 1999), p. 7.

${ }^{69}$ Nesse sentido, no contexto da UE, ver: C. Geiger, "The Construction of Intellectual Property in the European Union: Searching for Coherence”, in: C. Geiger (ed.), Constructing European Intellectual Property, supra nota 10, p. 5, advogando que futuras atividades do legislador europeu precisam ser baseadas mais freqüentemente na seriedade (e acima de tudo) em dados econômicos e importantes estudos que tornem possível mesurar as possíveis conseqüências da atividade do legislador. Ver também o relatório do professor I. Hargreaves, "Digital Opportunity, A Review of Intellectual Property and Growth”, maio de 2011, p. 1, convidando o legislador a "assegurar que no futuro, questões de política da propriedade intelectual sejam construídas nas bases da evidência, porém não no peso do lobby”.
} 
“implicam que os benefícios econômicos de um trabalho sejam em princípio de propriedade do autor; a proteção constitucional dos direitos de propriedade não se estendendo a todos esses benefícios. É a legislatura que determina os contornos do direito de autor pela imposição de critérios apropriados que levem em consideração, de um lado, a função social do direito de autor e assegurem, de outro, que o autor participe justamente da exploração de seu trabalho.,70 O legislador é sujeitado a uma obrigação de moderação. A obrigação de balanceamento é acentuada pelo fato de que é requerido da legislatura, quando estabelecendo os contornos do direito, o respeito a outros direitos fundamentais de valor equivalente; ${ }^{71}$ é por essa razão, ademais, que toda a legislação em direitos de propriedade intelectual deve impor certas limitações e exceções aos direitos exclusivos. Assim, em grande medida, a vinculação dos direitos de propriedade intelectual aos direitos fundamentais garante o respeito à função social desses direitos. ${ }^{72}$ Em termos práticos, pode ser questionado se a obrigação de proteger outros direitos fundamentais não implicaria na obrigação de o legislador também promulgar deveres para os titulares. ${ }^{73}$ Filosoficamente, isso estaria claramente em sintonia com a ideia do contrato social sublinhando a função social, o que implica em contrapartidas. Como interessantemente indicou um acadêmico, “a concessão de um direito de propriedade intelectual pode ser em si um derivativo de outros deveres, ou seja, quando o titular adquire um direito de propriedade intelectual, um dever para com o público é simultaneamente imposto ao titular.,74

Tais obrigações impostas aos titulares poderiam, por exemplo, resultar de um dever de disseminar de maneira a mais ampla possível as criações e explorá-las. Elas podem também negar a proibição da disseminação de trabalhos protegidos - por exemplo, ao atuar nos trabalhos órfãos, trabalhos não mais publicados, práticas restritivas contratuais e medidas de proteção

\footnotetext{
${ }^{70}$ Tribunal Constitucional Federal alemão, decisão "Livro escolar", 7 de Julho de 1971, GRUR 481 (1972) (ênfase em itálico); IIC 394 (1972), com os comentário de W. Rumphorst.

${ }^{71}$ C. Geiger, "Reconceptualizing the Constitutional Dimension of Intellectual Property", breve in: P. Torremans (ed.), Intellectual Property and Human Rights (Austin/ Boston/ Chicago/ New York, The Netherlands, Kluwer Law International, $3^{\mathrm{a}}$ edição, 2015); “Copyright's Fundamental Rights Dimension at EU Level", in: E. Derclaye (ed.), Research Handbook on the Future of EU Copyright (Cheltenham, UK/ Northampton, MA, Edward Elgar, 2009), p. 27; “Intellectual 'Property' after the Treaty of Lisbon”, supra nota 59; "Fundamental Rights as Common Principles of European (and International) Intellectual Property Law", in: A. Ohly (ed.), Common Principles of European Intellectual Property Law (Mohr Siebeck, Tübingen, 2012), p. 223.

${ }^{72}$ C. Geiger, "Fundamental Rights, a Safeguard for the Coherence of Intellectual Property Law?”, supra nota 55.

${ }^{73}$ Para mais detalhes em relação às conseqüências legais da constitucionalização dos direitos de propriedade intelectual para os legisladores, ver C. Geiger, “'Constitutionalising' Intellectual Property Law?”, supra nota 38, p. 397 et seq.

${ }^{74}$ E.F. Judge, "Intellectual Property Law as an Internal Limit on Intellectual Property Rights and Autonomous Source of Liability for Intellectual Property Owners”, 27(4) Bulletin of Science, Technology \& Society 311 (2007). Em relação aos deveres dos autores no campo do direito de autor, ver:C. Colin, “The Author's Duty”, (224) RIDA 160 (2010).
} 
técnica bloqueando o acesso, bem como obrigações análogas. Os deveres dos titulares também visariam à permissão do discurso público para certas criações, como paródias, citações, reuso transformativo e outros. Como já podem ser observados, alguns desses deveres resultam das obrigações impostas pelos direitos fundamentais, como liberdade de expressão e informação, liberdade artística e de comércio. As obrigações positivas dos Estados de protegerem esses direitos poderiam implicar que mecanismos sejam inseridos na propriedade intelectual para assegurar esses valores.

Um desses mecanismos seria a concessão de direitos aos usuários, que poderiam ser protegidos pelos tribunais. ${ }^{75}$ As limitações aos direitos de PI que sejam baseadas nos direitos fundamentais, bem como aquelas que representem valores democráticos básicos, poderiam ser alçadas à categoria de direitos dos usuários (e não somente direitos a serem levados em conta), que sejam de igual valor aos direitos exclusivos. ${ }^{76}$ Como consequência, esses direitos deveriam ser considerados mandatórios, o que implicaria em que o exercício de limitações impostas pela lei não poderia ser contornado por cláusulas contratuais ${ }^{77}$ e deveriam prevalecer em relação às medidas técnicas de proteção. Os legisladores poderiam introduzir em suas legislações a proibição de que mecanismos técnicos de proteção, que impeçam usos privilegiados pela lei e franqueiem aos usuários meios legais para garantir tais exceções. Isso levaria à criação de um “direito subjetivo” em relação a uma exceção. No contexto europeu, tal ação pode ser mesmo deduzida da diretiva Infosoc. ${ }^{78}$ De acordo com o artigo 6(4) da diretiva, os Estados Membros deverão tomar "medidas apropriadas” para garantir o funcionamento de determinadas limitações

\footnotetext{
${ }^{75}$ Em favor de tais práticas de concessão positiva aos usuários, ver:R. Burell and A. Coleman, Copyright Exceptions: The Digital Impact (Cambridge, CUP, 2005), p. 279; T. Riis and J. Schovsbo, "User's Rights, Reconstructing Copyright Policy on Utilitarian Grounds”, EIPR 1 (2007); C. Geiger, "Copyright and Free Access to Information”, supra nota 18, p. 371 et seq. No contexto das medidas técnicas, ver:A. Ottolia, 'Preserving Users' Rights in DRM: Dealing with 'Judicial Particularism' in the Information Society”, 35 IIC 491 (2004).

${ }^{76}$ Ver: C. Geiger, "Die Schranken des Urheberrechts im Lichte der Grundrechte - Zur Rechtsnatur der Beschränkungen des Urheberrechts”, in: R.M. Hilty and A. Peukert (eds.), Interessenausgleich im Urheberrecht (Nomos, Baden-Baden, 2004), p. 143; C. Geiger, "De la nature juridique des limites au droit d'auteur", Propr. intell. 882 (2004). Ver também CCH Canadian Ltd. v. Law Society of Upper Canada, [2004] 1 SCR 339.

${ }^{77}$ A lei belga estatui explicitamente o caráter imperioso das limitações e exceções legais ao direito de autor (ver artigo 23bis da Lei belga de 30 de junho de 1994, o qual foi inserido pela lei de 31 de agosto de 1998, que promulgou a diretiva européia da base de dados). O caráter mandatório das exceções foi mantido pela lei belga de 22 de maio de 2005 (M.B., 27 de maio de 2005, 24997). Ver, igualmente,M.-C. Janssens, "Implementation of the 2001 Copyright Directive in Belgium", 37 IIC 50 (2006), exceto para trabalhos tornados acessíveis ao público nos termos contratuais (artigo $7^{\circ}$ ). Na França, tal natureza imperativa poderia ser deduzida das palavras do artigo L 122-5 do Código de Propriedade Intelectual, já que ele especifica que "o autor não pode proibir" os usos ali previstos. O Tribunal de Grande Instância (TGI) de Paris, em sua decisão de 10 de janeiro de 2006, 13 RLDI 24 (2006), até mesmo decidiu explicitamente que o direito à cópia privada era “d'ordre public", mandatório, e, portanto, que uma medida técnica não poderia prejudicar a possibilidade de fazer uma cópia de um CD. Porém, a Corte de Cassação vem decidindo contrariamente (28 de fevereiro de 2006, Recueil Dalloz 784 (2006)).

${ }^{78}$ Directive 2001/29/EC of the European Parliament and of the Council of 22 May 2001 on the harmonisation of certain aspects of copyright and related rights in the information society (InfoSoc), OJ No. L 167 of 22 June 2001, p. 10.
} 
na medida em que medidas técnicas sejam programadas. Contudo, a diretiva não especifica em que essas medidas poderiam consistir. Em argumentando, seria contrário às obrigações dos Estados, nos termos do artigo 15 do Pacto Internacional sobre Direitos Econômicos, Sociais e Culturais (PIDESC), do artigo 10 da Convenção Européia dos Direitos do Homem (CEDH), e à função social do direito de autor não assegurar aos beneficiários as exceções previstas no artigo 6(4) da diretiva.

Mais importante ainda, a ideia de que os usuários têm direitos de igual valor aparece em decisões do TJUE. ${ }^{79}$ Em particular, em sua recente decisão no caso UPC Telekabel, de março de 2014, o Tribunal considerou os direitos dos usuários para contrabalancear a desproporcionalidade da proteção ao direito de autor. ${ }^{80} \mathrm{O}$ Tribunal, ao obrigar as autoridades nacionais, ainda que para o conjunto limitado de circunstâncias, a conceder aos usuários as oportunidades procedimentais para desafiar injunções perante os tribunais, ${ }^{81}$ acaba por aceitar a ideia de que os direitos fundamentais, entre eles a liberdade de expressão, podem ser invocados não meramente como uma defesa, mas também como um direito. Desde UPC Telekabel, a ideia de usuários terem direitos foi reiterada no caso Ulmer, de setembro de 2014. Nominalmente, o Tribunal se referiu a um “direito acessório” dos usuários de digitalizarem trabalhos contidos nas coleções de bibliotecas públicas. ${ }^{82} \mathrm{Na}$ opinião do Tribunal, tal direito de comunicação de trabalhos por parte de estabelecimentos, como bibliotecas públicas, são decorrentes da exceção disposta no artigo 5(3)(n) da Infosoc para o propósito de pesquisa e estudo privado. À luz dos recentes julgados do TJUE, pode ser arguido que o Tribunal se move para uma compreensão dos direitos fundamentais como parte integral do direito autoral europeu e para o total reconhecimento da função social da PI e de suas racionalidades humanas, como mencionado acima.

Do outro lado do Atlântico, uma posição analogamente liberal foi tomada pela Suprema Corte do Canadá, na medida em que, desde sua inovadora decisão em Théberge ${ }^{83}$ e em

\footnotetext{
${ }^{79}$ Ver:TJEU, Caso C-117/13, Ulmer [2014], Julgamento do Tribunal (Quarta Secção) de 11de setembro de 2014, para. 43, ainda não publicado; CJEU, Caso C-201/13, Deckmyn [2014], supra nota 63, para. 26; TJEU, Caso C-314/12, UPC Telekabel [2014], supra nota 63, para. 57; TJEU, Caso C-467/08, Padawan [2010], Julgamento do Tribunal (Terceira Seç̧ão) de 21 de outubro de 2010, para. 43, ECR I-10055; TJEU, Caso C-145/10, Painer [2011], supra nota 63, para. 132. Ver:ECS, "Limitations and Exceptions as Key Elements of the Legal Framework for Copyright in the European Union”, supra nota 63.

${ }^{80}$ TJEU, Caso C-314/12, UPC Telekabel [2014], id.

${ }^{81}$ TJEU, Caso C-314/12, UPC Telekabel [2014], id., para. 57: “... por conseguinte, para que os direitos fundamentais consagrados pelo direito da União não se oponham à decretação de uma injunção como a que está em causa no processo principal, é necessário que as regras processuais nacionais prevejam a possibilidade de os internautas invocarem os seus direitos no órgão jurisdicional, uma vez conhecidas as medidas de execução tomadas pelo fornecedor de acesso à Internet” (ênfase em itálico).

${ }^{82}$ TJEU, Caso C-117/13, Ulmer [2014], supra nota 79, para. 43.

${ }^{83}$ Théberge v. Galerie d'Art du Petit Champlain Inc., [2002] 2 SCR 336.
} 
$\mathrm{CCH},{ }^{84}$ as decisões vêm de maneira crescente enfatizando "a mudança de uma visão autorcêntrica”para a "promoção do interesse público" e os “direitos dos usuários como parte essencial a ser perseguida pelos interesses públicos do direito de autor”. ${ }^{85}$ A Corte expressamente se referiu nesses casos ao "balanceamento próprio entre proteção e acesso" como um objetivo maior da regulamentação do direito de autor. Como analisado acima, as duas racionalidades subentendidas na proteção dos criadores também estão presentes no artigo $27^{\circ}$ da DUDHe no artigo 15 do PIDESC, integrando intrinsecamente os aspectos da proteção e do acesso.

Resumindo, pode ser afirmado que o legislador deve assegurar que a aplicação dos direitos fundamentais nos regimes de propriedade intelectual seja protegida da ordenação privada.Isso se aplica para as limitações e exceções legais que são justificadas pelas racionalidades dos direitos fundamentais, declaradas mandatórias, e aos mecanismos aplicados para garantir a sua efetividade, especialmente no ambiente digital, em que elas são colocadas em risco pelas medidas de proteção técnica e pelos contratoson-line.

B. A revisão do balanceamento de interesses no direito de autor: em direção a um novo paradigma?

1. Por um entendimento mais restritivo das condições de proteção

Ao se considerar os direitos de propriedade intelectual como exceções maiores ao princípio do uso livre, ${ }^{86}$ isso também deveria implicar em uma mudança da lei. Os direitos exclusivos teriam que ser concebidos estritamente e as exceções largamente, ou ao menos de uma maneira mais flexível. Essa nova percepção poderia ser atingida ao se introduzir um tipo de regra dos três passos para determinar o acesso à proteção.

a. Em direção a um teste dos três passos para ganhar acesso à proteção ao direito de autor?

\footnotetext{
${ }^{84}$ CCH Canadian Ltd. v. Law Society of Upper Canada, [2004] 1 SCR 339.

${ }^{85}$ SOCAN v. Bell Canada, [2012] 2 SCR 326, paras. 9-11. Ver também Alberta (Ministro da Educação) v. Canadian Copyright Licensing Agency (Access Copyright), [2012] 2 SCR 345. Para uma excelente análise das decisões da Suprema Corte a respeito do direito dos usuários, ver: D. Vaver, "User Rights", 25 Intellectual Property Journal 105 (2013). Ver também: P. Chapdelaine, "The Ambiguous Nature of Copyright Users’ Rights”, 26 Intellectual Property Journal 1 (2013).

${ }^{86}$ VerC. Geiger, "Fundamental Rights, a Safeguard for the Coherence of Intellectual Property Law?", supra nota 55.
} 
A ideia de se ter um teste para determinar o acesso à proteção é comum em países como o Reino Unido, em que os juízes, por muito tempo, o chamaram de "skill-and-labour-test" para decidir se uma criação poderia ou não ser protegida. ${ }^{87}$

Nesse sentido, seria interesse elaborar certos critérios que uma expressão teria que satisfazer para obter a proteção legal. O conceito de fair usenorte-americano ou o teste dos três passos, que determina critérios para usos permitidos, poderia servir como modelo, considerando, todavia, que o teste seria invertido. Seria um teste para definir as limitações e não as condições para a proteção.

Quais seriam esses critérios? Primeiro, para se ter uma aproximação uniforme entre o direito costumeiro e o direito continental, o critério da criatividade deve ser preferido em relação ao critério da originalidade, este último definido como "a impressão da personalidade do autor.” A originalidade é difícil de determinar e envolve um risco de arbitrariedade. Ademais, ao se referir à lei como um instrumento para promover a criatividade, a propriedade somente poderia ser atribuída se há pelo menos uma contribuição criativa ou um enriquecimento coletivo. Nesse sentido, de agora em diante, deveria ser o degrau de criatividade o divisor de águas.

A professora Mireille Buydens, da Universidade de Bruxelas, sugeriu uma distinção muito interessante entre uma criação protegida pelo direito de autor e uma “quase-criação," que poderia se beneficiar de um tipo diferente de proteção. De acordo com ela, é a liberdade da qual o criador dispõe que deveria constituir o critério distintivo. ${ }^{88}$ Consequentemente, para decidir se um trabalho deveria receber proteção pelo direito de autor ou por um direito sui generis - um tipo de proteção ao investimento - o tribunal deveria analisar essencialmente se o criador esteve livre durante o processo de criação ou se sua liberdade de criação foi apenas acessória, uma vez que ele teve que atender a uma séria de necessidades. Por exemplo, a liberdade de um designer que cria móveis é na maioria das vezes limitada por constrições funcionais (uma cadeira tem que seguir determinadas características), constrições causadas pelo método de produção (custos, séries de produção) e constrições geradas pelo gosto do público (tendências em voga). ${ }^{89}$

\footnotetext{
${ }^{87}$ Ver, por exemplo, High Court of Justice, Chancery Division, 7 de abril de 2006, 2006 EWHC 719 e Court of Appeal, Civil Division, 28 de março de 2007, WC2A 2LL.

${ }^{88}$ M. Buydens, "La protection de la quasi-création" (Brussels, Larcier, 1989), p. 252. Ver também M. Buydens, "The Conditions and Scope of Copyright Protection", in: R.M. Hilty and C. Geiger (eds.), "The Balance of Interests within Copyright Law", Procedimentos da Conferência organizada em Berlim pelo Instituto Max Planck para a Propriedade Intelectual, de 4 a 6 de novembro de 2004, Munique, 2006, disponível em <www.intellecprop.mpg.de>.

${ }^{89}$ M. Buydens, "La protection de la quasi-création”, id., p. 276. O critério de liberdade do designer é usado para determinar o escopo de proteção no campo do desenho industrial (verartigo 9(2) da Diretiva 98/71/CE do Parlamento Europeu e do Conselho de 13 de Outubro de 1998 relativa à proteção legal de desenhos e modelos, JOCE L 289/28, de 28 outubro 1998: "Na apreciação do âmbito de proteção, deve
} 
O critério distintivo entre uma criação e uma quase-criação é se a liberdade do criador foi principal ou acessória. Se as necessidades que dizem respeito à função, tipo, estilo corrente e métodos de produção são predominantes, o trabalho tem que ser excluído da proteção. Uma vez que várias criações seriam excluídas, a professora Buydens sugere criar um sistema específico para as quase-criações, complementar aos instrumentos legais já existentes (o desenho industrial em particular). Evidentemente, existe uma necessidade de visar novas soluções para melhorar instrumentos já existentes. Aqui não é o lugar de esmiuçar todos os detalhes, mas isso já demonstra que existem formas de obter critérios mais objetivos para reputar uma criação protegida ou não. Além disso, o juiz também poderia levar em consideração as consequências que tal proteção poderia ter para outras criações futuras, da mesma forma que para a disponibilidade de informação e para o interesse público. Isso também significaria que os tribunais deveriam levar em conta considerações de direitos fundamentais ao decidir se um trabalho deve ou não ser protegido. ${ }^{90}$ Com efeito, interesses públicos, tais como aqueles ilustrados pelo direito da concorrência e outros direitos fundamentais, geralmente justificando a permissão de um uso, poderiam ser levados em consideração já no nível da proteção. Dessa maneira, algumas formas poderiam ser excluídas, devido a sua importância para a sociedade, seguindo o exemplo do artigo 2(4) da Convenção de Berna de 1886, ${ }^{91}$ o que implicaria em dar ao domínio público uma definição positiva. ${ }^{92}$ Tomemos o exemplo de um fotógrafo que capturou o assassinato de uma pessoa famosa ou a carta de um importante político que foi envolvido em um escândalo de corrupção. Seria possível levar em consideração a liberdade de expressão e o interesse público à informação (artigo $10 \mathrm{CEDH)} \mathrm{no} \mathrm{momento} \mathrm{de} \mathrm{decidir} \mathrm{se} \mathrm{essa}$ expressão deveria ser protegida ou não, e recusar a proteção pelo direito de autor em função de interesses públicos motivados.

Incidentalmente, certas decisões parecem indicar uma mudança de posicionamento nessa direção. Por exemplo, o tribunal regional de Dusseldorf, em sua decisão de 25 de abril de $2007,{ }^{93}$ recusou proteção a uma simples apresentação de uma notícia jornalística na ausência de

ser tomado em consideração o grau de liberdade de que o criador dispôs na realização do seu desenho ou modelo.".

${ }^{90}$ Ver: C. Geiger, ““Constitutionalising’ Intellectual Property Law?”, supra nota 38.

${ }^{91}$ Artigo 2(4): “Os países da União reservam-se a faculdade de determinar, nas legislações nacionais, a proteção a conceder aos textos oficiais de caráter legislativo, administrativo ou judiciário, assim como as traduções oficiais desses textos.”

92 Essa noção e o conteúdo do domínio público não foram ainda clarificados na literatura legal. Ver: J. Litman, “The Public Domain”, 39 Emory Law Journal 965 (1990); J. Boyle (ed.), “The Public Domain”, 66(1)-(2) Law \& Contemp. Probs. (2003); P.B. Hugenholtz and L. Guibault (eds.), The Public Domain of Information (The Hague, Kluwer Law International, 2006); S. Dusollier and V.-L. Benabou, "Draw Me a Public Domain”, in: P. Torremans (ed.), Copyright Law: A Handbook of Contemporary Research (Cheltenham, UK/Northampton, MA, USA, Edward Elgar, 2007). Contrariamente ao setor ambiental, a preservação de recursos informativos não foi assegurada ainda.

93 Tribunal regional de Dusseldorf (primeira instância), Caso No. 120 194/06, 25 de abril de 2007. 
individualidade.De maneira similar, o Tribunal de Apelação de Amsterdã $^{94}$ recusou a proteção à gravação de uma conversa publicada em um livro, ao fundamento de que a pessoa que respondia às perguntas não teve intenção ao criar o trabalho. ${ }^{95}$ Mesmo que o tribunal não tenha se referido ao artigo 10 da CEDH, parece que ele implicitamente balanceou os interesses dos titularescom aqueles do público, considerando o direito de ser informado já no nível da proteção ao trabalho e permitindo com que o direito à informação prevalecesse. Similarmente, quando as cortes francesas excluem radicalmente a proteção à fragrância de perfumes pelo direito de autor, isso não deixa de ser um esforço para limitar o campo de expansão. ${ }^{96}$

b. formulando um teste dos três passos para acessar à proteção ao direito de autor

As considerações feitas acima levariam a seguinte cláusula geral: "somente expressões que sejam o resultado de um processo criativo em que a liberdade do criador foi superior às constrições impostas e que não interfira indevidamente no futuro de outras criações, nem causem um prejuízo injustificável aos interesses do domínio público, tais como a participação cultural, podem receber a proteção pelo direito de autor.” Assim, a função do acesso ao direito de autor seria determinada por um teste de três passos apropriado, servindo para guiar os juízes. Claro que o primeiro critério seria preponderante, embora os demais devam servir como possíveis corretivos, principalmente se a exclusão de uma forma de proteção tivesse impacto considerável para a inovação. Esse poderia ser o caso, por exemplo, se uma forma for considerada como essential facility, i.e, que o seu uso em particular seja necessário para acessar

\footnotetext{
${ }^{94}$ Tribunal de Apelação de Amsterdã, Endstra's Sons v. Middelburg, Vugts e Nieuw Amsterdam, 8 de fevereiro de 2007, (4) AMI (2007).

${ }^{95}$ Note, todavia, que essa decisão foi recorrida e chegou ao Tribunal Supremo holandês, que concluiu que a proteção ao direito de autor na ausência da intenção de criar não seria impossível por definição. $O$ Tribunal estatuiu que embora fosse verdade que um trabalho humano e, portanto, escolhas criativas, sejam relevantes, a questão se o autor queria intencionalmente criar o trabalho ao fazer determinadas escolhas originais não são importantes para a proteção (Suprema Corte Holandesa, Endstra's Sons v. Middelburg, Vugts e Nieuw Amsterdam, Caso No. C07/131HR, 30 de maio de 2008. Para um comentário, ver: B. Beuving, "Endstra's Final Work? Dutch Copyright: Scope of Protection Remains Very Wide", Bird \& Bird Copyright Update 24 (fevereiro de 2009), p. 26. Para uma segunda e final apelação desse caso, ver: Tribunal de Apelação de Amsterdã, Endstra's Sons v. Middelburg, Vugts e Nieuw Amsterdam, 16 de julho de 2013.

${ }^{96}$ Ver: Corte de Cassação, $1^{\text {a }}$ Divisão Cível, 13 de junho de 2006, 37 IIC 988 (2006): “A fragrância de um perfume, que resulta de uma simples aplicação de savoir-faire, não constitui uma criação de uma forma de expressão capaz de beneficiar de uma proteção pelo direito de autor para trabalhos do espírito, no sentido dos artigos L. 112-1 e L. 112-2 do Código de Propriedade Intelectual”. Todavia, desde então, os tribunais inferiores vem recusando seguir a decisão da Corte e continuam a conceder proteção. Ver: Tribunal de Grande Instância de Bobigny, 28 de novembro de 2006, Comm. com. électr. (fevereiro de 2007), p. 13, comentário de C. Caron e Corte de Apelação de Paris, $4^{a}$ Câmara A, 14 de fevereiro de 2007, 39 IIC 113 (2008).
} 
determinado mercado. Todas essas considerações também podem ser levadas em conta na análise das limitações. O objetivo do segundo passo, por exemplo, poderia ser atingido pela aplicação de uma exceção para o uso criativo. ${ }^{97}$ Todavia, pode ser considerado mais insatisfatório conceder proteção onde as consequências para a inovação e a criatividade sejam maisprejudiciais do que considerar a proteção por meio de um complicado mecanismo de exceção. Se o aspecto do acesso ao direito de autor é considerado seriamente como um direito inalienável, a concessão de proteção às criações que possam ser consideradas como um revés para futuras criações não deveria ser permitida em primeiro lugar. Mesmo que os juízes já possam considerar essa lógica na elegibilidade de proteção a um trabalho, a aplicação legal desse novo teste de três passos seria desejável para dar mais transparência aos players econômicos.

Ao seguir esse procedimento, a teoria francesa da "unité de l'art" teria que ser provavelmente abandonada. De acordo com essa teoria, a proteção pelo direito de autor não é excluída em função da utilidade de um objeto, e perderia aqui todo o interesse. Com efeito, ou o criador gozou de liberdade suficiente no processo de criação e deve receber proteção ou o fator criativo foi apenas acessório em função de várias necessidades, razão pela qual ele terá que emigrar para outro sistema de proteção (e.g, desenho industrial). Consequentemente, alguém não deveria ter que distinguir se um trabalho foi predominantemente criativo ou funcional. É verdade que algumas criações periféricas podem ser desclassificadas como objetos funcionais. Esse, todavia, é o preço a ser pago para "purificar” o direito de autor de determinadas formas e garantir viabilidade à informação (nada mais do que ideias colocadas em formas). Esses trabalhos não deixarão de ser protegidos; somente não serão protegidos por um sistema forte e durador como o do direito de autor, mas por outros mecanismos de proteção existentes ou que tenham que ser criados. ${ }^{98}$

2. Uma compreensão extensiva/flexível das limitações do direito de autor

Como demonstrado acima, levando em consideração que a aproximação do uso livre (liberdade de expressão, liberdade de ciência e artes) representa o princípio, e os direitos exclusivos representam a exceção, limitações à exclusividade não podem ser consideradas como exceções, antes devem ser consideradas como o princípio. No final, a demanda por uma

\footnotetext{
${ }^{97}$ Ver: C. Geiger, “Copyright and the Freedom to Create, A Fragile Balance”, 38 IIC 707 (2007).

${ }^{98}$ Advogando pela criação de um mecanismo de proteção ao investimento, ver:R.M. Hilty, "The Law Against Unfair Competition and its Interfaces”, in: R.M. Hilty and F. Henning-Bodewig (eds.), Law Against Unfair Competition, Towards a New Paradigm in Europe" (Berlin/Heidelberg/New York, Springer, 2007), p. 1.
} 
proteção mais extensiva e rigorosa, ${ }^{99}$ da mesma forma que o postulado da interpretação restritiva às limitações ao direito de autor, representaria nada mais do que um discurso político. Nesse contexto, o que realmente seria importante é se a regulação ao direito de autor atinge seu propósito e não qual técnica legal, direito exclusivo ou limitação, é usada. Com efeito, as “exceções”" não são mais do que ferramentas para que o legislador determine o escopo do direito e para manter o balanceamento entre os direitos dos titulares e usuários. ${ }^{101}$ Assim, elas deveriam ser interpretadas tendo em vista suas justificativas. Ao se considerar a hipótese de que o direito de autor serve à sociedade ao encorajar a criação de novos trabalhos, é necessário deixar espaço suficiente para a livre criatividade.

Mais ainda, mesmo em termos econômicos, o valor das limitações pode ser medida de inúmeras formas, tipicamente ao se mostrar os benefícios de um dado sistema. ${ }^{102}$ Existem várias formas de negócios que usam materiais "livres”, isto é, materiais cujo uso é permitido por uma limitação - os chamados added value services - para gerar ganhos e crescimento econômico. ${ }^{103}$ Mesmo se a limitação prevê o pagamento de uma remuneração, a ausência de custos relacionados à dificuldade de localizar um titular, ao processo de negociação de uma licença e, em alguns casos, os custos associados ao litígio, também teriam um valor mensurável para permitir a reutilização de trabalhos existentes.

Em alguns casos, a mudança nas circunstâncias técnicas e sociais poderia requerer uma interpretação extensiva e mesmo a criação de novas exceções por analogia, mesmo que

\footnotetext{
${ }^{99}$ Nesse sentido, no contexto europeu, ver e.g: recital 11 à Directiva 2001/29/EC, supra nota 78; recital 16 à Diretiva 2006/115/CE do Parlamento Europeu e do Conselho, de 12 de Dezembro de 2006, relativa ao direito de aluguel, ao direito de comodato e a certos direitos conexos ao direito de autor em matéria de propriedade intelectual (versão codificada), JO No. L 376, de 27 de dezembro de 2006, p. 28. Ver também Comissão das Comunidades Européias, Green Paper: Copyright in the Knowledge Economy (Bruxelas, COM, 2008, 466 final), p. 4.

${ }^{100}$ Nossa específica interpretação do termo "limitação" parece mais apropriada. Para a distinção entre "limitação" e "exceção", ver:C. Geiger, "Promoting Creativity through Copyright Limitations: Reflections on Concept of Exclusivity in Copyright Law", 12(3) Vanderbilt Journal of Entertainment \& Technology Law 515 (2010), p. 518 et seq

${ }^{101}$ Em particular, ver: P.B. Hugenholtz, "Adapting Copyright to the Information Superhighway", in: P.B. Hugenholtz (ed.), The Future of Copyright in a Digital Environment (The Hague, Kluwer, 1996), p. 94; M. Vivant, "La limitation ou 'réduction' des exceptions au droit d'auteur par contrats ou mesures techniques de protection. De possibles contrepoids?”, Relatório Geral apresentado em Dias de Estudo da ALAI, Barcelona, 19 a 20 de junho de 2006; C. Geiger, "Der urheberrechtliche Interessensausgleich in der Informationsgesellschaft”, GRUR Int. 815 (2004).

${ }^{102}$ Ver: L. Gibbons, "Valuing Fair Use", Paper Presentation at the Conference on Innovation and Communication Law, University of Turku, Finland (17 de julho de 2008).

${ }^{103}$ T. Rogers and A. Szamosszegi, Fair Use in the U.S. Economy: Economic Contribution of Industries Relying on Fair Use (Computer \& Communications Industry Association, 2011); L. Gibbons and X.L. Wang, "Striking the Rights Balance Among Private Incentives and Public Fair Uses in the United States and China”, 7 J. Marshall Rev. Intell. Prop. L. 488 (2008), p. 494.
} 
para além da lei. ${ }^{104}$ "Congelar” o status quo das exceções implicaria, ao contrário, na inadaptabilidade do sistema. É importante levar em consideração que o sistema das limitações não mudou muito nos países europeus e, onde ele de fato mudou, tal mudança nunca atingiu a expectativa que seria necessária a uma verdadeira adaptação do direito de autor à "sociedade da informação". Muitos autores apontaram que a diretiva Infosoc falhou nesse sentido, ${ }^{105}$ ao somente prever uma lista facultativa de exceções, de maneira que o legislador europeu não obrigou o legislador nacional a modernizar suas legislações. ${ }^{106}$ Desse modo, há dúvidas justificáveis se a legislação não seria ainda "velha," de maneira que os tribunais estão agora seguindo uma nova tendência ao renunciar ao princípio da interpretação restritiva para realizar raciocínios por analogia ${ }^{107}$ e criar exceções para além da lei. Mesmo a França, um país que é conhecido por manter uma interpretação bastante restritiva das exceções ao direito de autor, conhece agora juízes que criaram exceções à reprodução acessória, ${ }^{108}$ mesmo que para além da lei.

É verdade que, ao contrário dos países que contam com o fair use, o sistema continental não prevê ao juiz um instrumento adequado para lidar com as exceções. O teste dos três passos incorporado na diretiva Infosoc, todavia, pode permitir aos juízes aplicar exceções de uma maneira mais flexível. ${ }^{109}$ De acordo com o artigo 5(5) da diretiva, "As exceções e limitações [...] só se aplicarão em certos casos especiais que não entrem em conflito com uma

\footnotetext{
${ }^{104}$ Nesse sentido, por exemplo, ver: M. Buydens e S. Dusollier, "Les exceptions au droit d'auteur: évolutions dangereuses”, Comm. com. électr. (September 2001), p. 11; C. Geiger, "Creating Copyright Limitations Without Legal Basis: The ‘Buren’ Decision, a Liberation?”, 36 IIC 842 (2005); J.-C. Galloux, "Les exceptions et limitations au droit d'auteur: exception française ou paradoxe français?", in: R.M. Hilty and C. Geiger (eds.), Impulse für eine europäische Harmonisierung des Urheberrechts (Berlin/Heidelberg/New York, Springer, 2007), p. 329 et seq. Todavia, tem que ser admitido também que inúmeras vozes urgem no sentido oposto.

${ }^{105}$ Ver e.g.: R.M. Hilty and M. Vivant, "La transposition de la directive sur le droit d'auteur et les droits voisins dans la société de l'information en Allemagne et en France, Analyse critique et prospective”, in: R.M. Hilty and C. Geiger (eds.), Impulse für eine europäische Harmonisierung des Urheberrechts, id., p. 51,71 .

${ }^{106}$ Nesse sentido, o estudo conduzido pelo IViR, da Universidade de Amsterdã: "The Recasting of Copyright and Related Rights for the Knowledge Economy”, novembro, 2006 (www.ivir.nl), p. 75, que recomenda que certas limitações deveriam ser declaradas obrigatórias para assegurar a efetiva harmonização.

${ }^{107}$ Ver, por exemplo, a decisão do Supremo tribunal holandês de 20 de outubro de 1995 nos procedimentos entre Dior v. Evora (1996 NJ 682), em que se estima que não seja proibido o recurso pelo juiz à analogia para contextos não previstos pela legislatura.

${ }^{108}$ Corte de Cassação, $1^{a}$ Divisão Cível, 15 de março de 2005, 36 IIC 869 (2005). Ver também C. Geiger, "Creating Copyright Limitations Without Legal Basis", supra nota 104 e Corte de Apelação de Bordeaux, 13 de junho de 2006, (238) Légipresse 5 (2007), comentário de A. Maffre-Baugé em relação à reprodução de uma imagem no contexto de uma reportagem que analisava a audiência de uma corte famosa.

${ }^{109}$ Nesse sentido, ver:M. Senftleben, “The International Three-Step Test: A Model Provision for EC Fair Use Legislation", 1(2) Journal of Intellectual Property, Information Technology and E-Commerce Law 67 (2010) e do mesmo autor "Comparative Approaches to Fair Use: An Important Impulse for Reforms in EU Copyright Law”, in: G.B. Dinwoodie (ed.), Intellectual Property Law: Methods and Perspectives, supra nota 11; C. Geiger, "The Role of the Three-Step Test in the Adaptation of Copyright Law to the Information Society”, e-Copyright Bulletin (janeiro-março de 2007).
} 
exploração normal da obra ou outro material e não prejudiquem irrazoavelmente os legítimos interesses do titular do direito.” ${ }^{110} \mathrm{O}$ juiz, responsável por aplicar a exceção, poderá usar esse instrumento para adaptar as exceções às circunstâncias que ainda não foram previstas em lei. ${ }^{111}$ Com efeito, essa flexibilidade não precisa levar a uma redução ainda maior das exceções. Sendo o juiz livre, sua liberdade de ação deveria ser usada não somente para reduzir, mas para também expandir as limitações. ${ }^{112}$ É verdade que isso pode comprometer a segurança jurídica. Ainda assim, isso seria o preço a ser pago para aplicar exceções mais refinadas e que possam se adequar melhor às novas circunstâncias. Do contrário, o teste inteiro deveria ser rejeitado se o seu uso somente trás benefícios ao titular e nenhum benefício aos usuários.

O terceiro passo do teste lida com as justificativas que subjazem às limitações. É a parte mais importante do teste. De acordo com este, a aplicação de limites ao direito de autor não deve ser injustificável, considerando os legítimos interesses do titular. A razão para essa etapa do teste é que o autor não deveria estar em uma posição que lhe permitisse controlar todos os usos de seu trabalho; antes, ele tem que tolerar certas interferências, desde que sejam justificadas por valores que sejam superiores aos interesses dos titulares. ${ }^{113}$ Essa fórmula permitirá ao juiz aplicar um tipo de controle de proporcionalidade que é usado no caso de conflito entre direitos fundamentais. ${ }^{114} \mathrm{Em}$ tais casos, o juiz deve levar em consideração as justificativas de cada limitação e os diferentes interesses fundamentais envolvidos para atingir um balanceamento refinado.Ao se combinar, de um lado, os sistemas fechados de exceções e, de outro, o método flexível do fair use, um interessante resultado seria atingido: não somente

\footnotetext{
${ }^{110} \mathrm{O}$ teste dos três passos é conhecido por uma composição similar, embora não idêntica, em vários instrumentos internacionais da propriedade intelectual, como o artigo 9(2) da Convenção de Berna (para o direito de reprodução), artigo 13 do TRIPS (para todos os direitos de exploração), e os artigos 10 e 16, respectivamente, dos tratados da OMPI em relação ao direito de autor (WCT) e em relação ao direito dos intérpretes e produtores de fonograma (WPPT). Ver:C. Geiger, D. Gervais, and M. Senftleben, "The Three-Step-Test Revisited: How to Use the Test's Flexibility in National Copyright Law", 29(3) American University International Law Review 581 (2014).

${ }^{111}$ Esse é especialmente o caso, na medida em que algumas legislações incorporaram o teste dos três passos no nível doméstico (na França, por exemplo, no artigo L. 122-5 do CPI). Desde então, é incontestável que o teste será usado pelas cortes para interpretar as exceções. Ver:C. Geiger, "From Berne to National Law, via the Copyright Directive: The Dangerous Mutations of the Three-Step Test”, EIPR 486 (2007).

${ }^{112}$ De qualquer maneira, parece que o TJUE, na decisão Infopaq, de 16 de julho de 2009 entendeu que o teste dos três passos do artigo 5(5) implica em uma interpretação restritiva das exceç̃̃es ao direito de autor (CEJ, Caso C-5/08, Infopaq [2009], Julgamento do Tribunal (Quarta Secção) de 16 de julho de 2009, paras. 56-58, ECR I-06569).

${ }^{113}$ A Tribunal Constitucional alemão clarificou a questão muito bem em sua decisão "Livro escolar”, de 7 de julho de 1971, supra nota 70.

${ }^{114}$ M. Senftleben, Copyright, Limitations and the Three-Step Test (The Hague, Kluwer, 2004), p. 226; S. Dusollier, "L'encadrement des exceptions au droit d'auteur par le test des trois étapes", IRDI 213 (2005), p. 221; C. Geiger, “The Three-Step Test, A Threat to a Balanced Copyright Law?”, 37 IIC 683 (2006), p. 696; T. Sinodinou, "Voyage des sources du test des trois étapes aux sources du droit d'auteur", (30) RLDI (2007) p. 67.
} 
interesses econômicos seriam levados em consideração, como também interesses divergentes de usuários, bem como os interesses do autor, na medida em que estes sejam diferentes dos interesses do intermediador. ${ }^{115}$ Infelizmente, a aplicação do teste pelos tribunais tem sido realizado de maneira restritiva, ${ }^{116}$ uma vez que os critérios foram interpretados de modo a favorecer claramente os titulares. Porém, no futuro, os juízes serão livres para interpretar o teste de uma maneira diferente. Eles poderiam se inspirar em alguns acadêmicos que propuseram outras interpretações, ${ }^{117}$ de modo a tornar o teste um instrumento flexível e eficiente eao permitir com que as exceções legais sejam interpretadas de uma maneira mais extensiva.

C. A garantia do interesse material dos criadores: um aspecto crucial do direito de autor como um direito ao acesso

Estabelecer o direito de autor como um direito ao acesso e à cultura não implica admitir esse processo como gratuito. Com efeito, um aspecto essencial do direito de autor como um direito ao acesso, no espírito dos instrumentos internacionais de direitos fundamentais, é a garantia de que seus interesses morais e materiais sejam resguardados. Isso certamente implica que os sistemas de direito de autor devem, de uma melhor maneira, considerar os autores, o que significa que eles devem participar de uma maneira mais efetiva na exploração de seus trabalhos. Como isso seria atingido, todavia, é secundário. Alguém poderia imaginar, por exemplo, uma melhor lei contratual, ${ }^{118}$ com regras mandatórias, que já existem em algumas leis de países europeus, como também o aumento da oferta de licenças legais se elas implicam em melhor remuneração ao autor do que direitos exclusivos. Essa última via permanece

\footnotetext{
${ }^{115}$ De fato, autores e intermediários podem ter interesses bem diferentes, especialmente em relação à adoção de mecanismos de proteção técnica. Nesse sentido, é importante consultar as palavras do teste dos três passos para clarificar essa perspectiva. Na Convenção de Berna e no Tratado da OMPI de 1996 são os "legítimos interesses do autor" que devem ser levados em conta; no TRIPS e na diretiva são os "legítimos interesses do titular". Se for realmente o autor que deve figurar no centro de interesses, como é freqüentemente declarado em países que seguem essa tradição, deve ser do interesse dos autores prevalecerem em relação aos intermediários no momento da interpretação do teste.

${ }^{116}$ Corte de Cassação, $1^{a}$ Divisão Cível, 28 de fevereiro de 2006, 37 IIC 760 (2006), comentários de C. Geiger (p. 683).

${ }^{117}$ Ver Geiger, D. Gervais, and M. Senftleben, "The Three-Step-Test Revisited", supra nota 110; M. Senftleben, "The International Three-Step Test", supra nota 109; e, do mesmo autor, "Comparative Approaches to Fair Use”, supra nota 109; C. Geiger, "The Role of the Three-Step Test in the Adaptation of Copyright Law to the Information Society", supra nota 109; K.J. Koelman, "Fixing the Three-Step Test", EIPR 407 (2006).

${ }^{118}$ Ver e.g.: R.M. Hilty, "Five Lessons About Copyright in the Information Society: Reaction of the Scientific Community to Over-Protection and What Policy Makers Should Learn”, 53 Journal of the Copyright Society of the USA 127 (2006), p. 137.
} 
ISSN ELETRÔNICO 2316-8080

COPYRIGHT COMME UN DROIT A GARANTIR L'ACCES A LA PARTICIPATION CULTURELLE PAR LA PROTECTION DES INTERETS DES CREATEURS

relativamente não explorada e requer uma análise cuidadosa. ${ }^{119}$ Considerando a perspectiva dos direitos fundamentais, a DUDH, tampouco o PIDESC, determinam a maneira como a proteção aos interesses materiais e morais poderiam ser atingidos. Não há menção expressa aos direitos exclusivos ou à propriedade, o que significa que, no escopo desses tratados, outros meios de proteção podem ser igualmente concebidos. ${ }^{120}$ Isso permite aos legisladores espaço de manobra, ao mesmo tempo em que garantindo aos criadores uma justa remuneração por seus trabalhos, tornando tais instrumentos modernos e flexíveis para regular a propriedade intelectual. ${ }^{121}$

Em resumo, os regimes de direito de autor devem assegurar com que os criadores participem justamente de seus ganhos pela exploração comercial de suas criações. Isso não precisa ser necessariamente feito por meio do direito de propriedade. Os legisladores têm a sua disposição a liberdade para escolherem entre os meios legais disponíveis para assegurar uma justa remuneração aos autores.

Conclusão

Uma investigação nas bases de proteção da propriedade intelectual demonstra que suas justificativas foram colocadas de lado em favor da proteção ao investimento e que o balanceamento do sistema pende em favor dos intermediadores da propriedade intelectual. Essa conclusão não é nova, na medida em que esse paradigma já havia sido notado pela literatura da década de oitenta, ${ }^{122}$ embora nenhuma conclusão real tivesse sido atingida na época. Assumindo, todavia, que as fundações do sistema se alteraram, as mesmas soluções não podem ser mais

\footnotetext{
${ }^{119}$ Essas ideias foram formuladas em relação ao direito de autor. Ver:C. Geiger, Droit d'auteur et droit du public à l'information, supra nota 18, p. 318 et seq.; R.M. Hilty, "Verbotsrecht vs. Vergütungsanspruch: Suche nach den Konsequenzen der tripolaren Interessenlage im Urheberrecht”, in: A. Ohly, T. Bodewig, T. Dreier, H.-P. Götting, M. Haedicke and M. Lehmann (eds.), Festschrift für Gerhard Schricker (Beck, Munich, 2005), p. 348 et seq. No contexto da cópia privada, verK. Gaita e A.F. Christie, "Principle or Compromise? Understanding the Original Thinking Behind Statutory License and Levy Schemes for Private Copying”, IPQ 426 (2004); A. Dietz, "Continuation of the Levy System for Private Copying also in the Digital Era in Germany", Auteurs et Médias (2003), p. 348 et seq.

${ }^{120} \mathrm{O}$ Comentário Geral No. 17, por exemplo, confirmou que a proteção à propriedade intelectual, mesmo que não excluindo a proteção conferida pelo direito de propriedade, pode, ainda, em certas circunstâncias, implicar em medidas compensatórias, como o pagamento ou a remuneração adequadas": CESCR, General Comment No. 17, supra nota 27, para. 24. Ver também C. Geiger, "Fundamental Rights as Common Principles of European (and International) Intellectual Property Law”, supra nota 71, p. 227.

${ }^{121}$ Ver: T. Mylly, "Intellectual Property and Fundamental Rights: Do they Interoperate?”, in: N. Bruun (ed.), Intellectual Property Beyond Rights (Helsinki, WSOY, 2005), p. 197; C. Geiger, "Fundamental Rights as Common Principles of European (and International) Intellectual Property Law”, id.

${ }^{122}$ Ver, e.g: A. Dietz, “Transformation of Authors' Rights, Change of Paradigm”, 138 RIDA (1988), p. 22.
} 
aplicadas, de maneira que estabelecer o direito de autor como um direito ao acesso e não como um direito de proibir ou sancionar se tornou extremamente necessário.

Como analisado, ambos os aspectos da proteção e do acesso estão intimamente ligados. Todavia, as tendências atuais de proteção excessiva podem requerer uma ênfase maior na participação cultural para restabelecer um balanceamento justo. Não deixa de assumir importância - a massiva rejeição da propriedade intelectual pela opinião pública é um claro indicar -, o fato de que o direito de autor ser definido como um direito cultural ou como um mecanismo de proteção ao investimento. Como demonstrado, (re)conceber a PI como um direito ao acesso, ${ }^{123}$ em particular o direito de autor, evitará a privatização da informação pela $\mathrm{PI},{ }^{124} \mathrm{bem}$ como assegurará que criações ainda estejam disponíveis para futuras inovações.

Recebido 02/06/2015

Aprovado 15/06/2015

Publicado 30/06/2015

\footnotetext{
${ }^{123}$ Nessa linha, em março de 2015, o relatório temático especial do Rapporteur das Nações Unidas no campo dos direitos culturais, que se devotará ao impacto dos sistemas de propriedade intelectual ao gozo de direitos como ciência e cultura, estipulados no artigo 15 do PIDESC. Para mais informações, ver o site do Office of the UN High Commissioner for Human Rights, "New Issue in Focus: The Impact of Intellectual Property Regimes on the Enjoyment of Right to Science and Culture", disponível em: <http:// www.ohchr.org/EN/Issues/CulturalRights/Pages/impactofintellectualproperty.aspx (acessado em 26 de novembro de 2014).

${ }^{124}$ Geiger, “Flexibilising Copyright”, supra nota 8.
} 